${ }^{2}$ Centro de Investigação, Formação, Intervenção e Inovação em Desport

Universidade do Porto, Portugal

https://doi.org/10.5628/rpcd.21.S2.284

\section{A diversidade na unidade. \\ Informação transversal e longitudinal.}

\section{Basquetebol}

(1)

\section{DOMÍNIO BIOLÓGICO. DESEMPENHO MOTOR:}

\section{CURVAS DA DISTÂNCIA E DA VELOCIDADE}

\section{INTRODUÇÃO}

Um dos principais desafios na descrição e interpretação da informação longitudinal do desempenho motor está na escolha da métrica temporal. Habitualmente é feita em função da idade cronológica e obtém-se uma curva da distância. Em contrapartida, se se quiser obter uma curva da velocidade há que recorrer a um procedimento matemático desenvolvido por Van't Hof descrito em Beunen et al. (1988). 0 procedimento permite representar, na mesma figura, as duas curvas - a da distância e a da velocidade (mostrada mais adiante).

Um dos indicadores mais importantes do sistema de maturação somática é a idade em que ocorre a maior velocidade de crescimento da altura, habitualmente designado por idade no pico de velocidade da altura (iPVA). É também em função dele que se classificam os sujeitos em atrasados, on time e avançados maturacionalmente.

Com base no procedimento de Van't Hof é possível identificar, também, a idade em que ocorreu o maior salto de desenvolvimento de um marcador contínuo do desempenho motor Como base nesta informação há quem refira a possibilidade de identificar janelas de desenvolvimento mais elevado (i.e., picos), de diferentes facetas do desempenho motor (sobre esta matéria ver, por exemplo, Guimarães et al., 2020; Philippaerts et al., 2006; Silva et al., 2019) No caso concreto do basquetebol, e a partir dos dados do INEX, um estudo recente de Guimarães et al. (2021) descreveu tais saltos, alinhados pela iPVA, para distintos marcadores da força muscular que podem configurar períodos sensíveis do seu desenvolvimento.
Neste trabalho apresentaremos as curvas da distância e da velocidade da força muscular (salto com contramovimento e lançamento da bola medicinal), corrida de velocidade, agilidade e performance aeróbia.

\section{RESULTADOS}

Força muscular

Em conformidade com o esperado em estudos longitudinais anteriormente referenciados, as curvas da distância do salto vertical com contramovimento e do lançamento sentado da bola medicinal (FIGURA 1) mostram que os jovens basquetebolistas melhoraram sistematicamente o seu desempenho entre os 12.0 e os 15.0 anos de idade, seguindo-se um ligeiro decréscimo em ambas as provas. Relativamente às curvas da velocidade (FIGURA 1), a idade média em que ocorreu o pico de desenvolvimento do desempenho em ambos os testes foi aos 13.9 anos de idade (i.e., coincidente com a iPVA).

Não obstante a literatura com jovens basquetebolistas ser omissa em estudos desta natureza, estes resultados corroboram, em parte, os referidos em três projetos de investigação de larga escala: o Ghent Youth Soccer Project (Philippaerts et al., 2006), o Leuven Growth Study of Belgian Boys (Beunen et al., 1988) e o Saskatchewan Growth Study (Ellis et al., 1975). No salto vertical com contramovimento, também Philippaerts et al. (2006), no estudo longitudinal-misto com jovens futebolistas belgas, identificaram um pico coincidente com o pico de velocidade da altura (PVA), enquanto Beunen et al. (1988), no estudo com jovens belgas não-atletas, identificaram-no seis meses após o PVA. Por outro lado, a intensidade dos picos foi ligeiramente inferior à encontrada no nosso estudo (basquetebolistas: intensidade $=5.50 \mathrm{~cm} \cdot \mathrm{ano}^{-1}$; futebolistas belgas: intensidade $=5.10 \mathrm{~cm} \cdot \mathrm{ano}^{-1}$; não-atletas belgas: intensidade $\left.=4.80 \mathrm{~cm} \cdot \mathrm{ano}^{-1}\right)$. É provável que o elevado número de saltos que os jovens jogadores de basquetebol realizam durante os treinos e jogos possam ser parcialmente responsáveis por estas diferenças (Janeira \& Maia, 1998).

No lançamento sentado da bola medicinal, os nossos resultados contrastam com os de Yagüe e De La Fuente (1998), dado que estes identificaram um pico nesta prova quatro meses após o PVA (intensidade $=1.38 \mathrm{~m}^{\cdot} \mathrm{ano}^{-1}$ ) numa amostra de jovens espanhóis não-atletas. No entanto, os nossos resultados são similares aos reportados com jovens futebolistas belgas (Philippaerts et al., 2006), quer com outras populações de jovens não-atletas belgas e canadianos (Beunen et al., 1988; Ellis et al., 1975), isto é, pico de desenvolvimento do desempenho coincidente com o PVA, apesar destes autores terem utilizado testes de suspensão na barra para medir a força muscular da parte superior do tronco e dos membros superiores. De qualquer modo, os resultados relativos à intensidade do pico merecem esclarecimentos adicionais, uma vez que nos basquetebolistas a intensidade $\left(0.75 \mathrm{~m} \cdot \mathrm{ano}^{-1}\right)$ foi menor que a reportada em rapazes não-atletas espanhóis (menos $0.63 \mathrm{~m}^{\prime} \cdot \mathrm{ano}^{-1}$ ). É possível que os distintos protocolos dos testes possam explicar tais diferenças, embora em 
ambos os estudos tenha sido utilizada uma bola medicinal de $3 \mathrm{~kg}$. Por exemplo, no nosso estudo os jovens basquetebolistas tinham de lançar a bola medicinal enquanto estavam sentados no chão, com os membros inferiores em extensão e as costas encostadas à parede, ao passo que no estudo conduzido em Espanha não é conhecido, em detalhe, o protocolo utilizado (lançamento sentado, em pé ou por cima da cabeça).
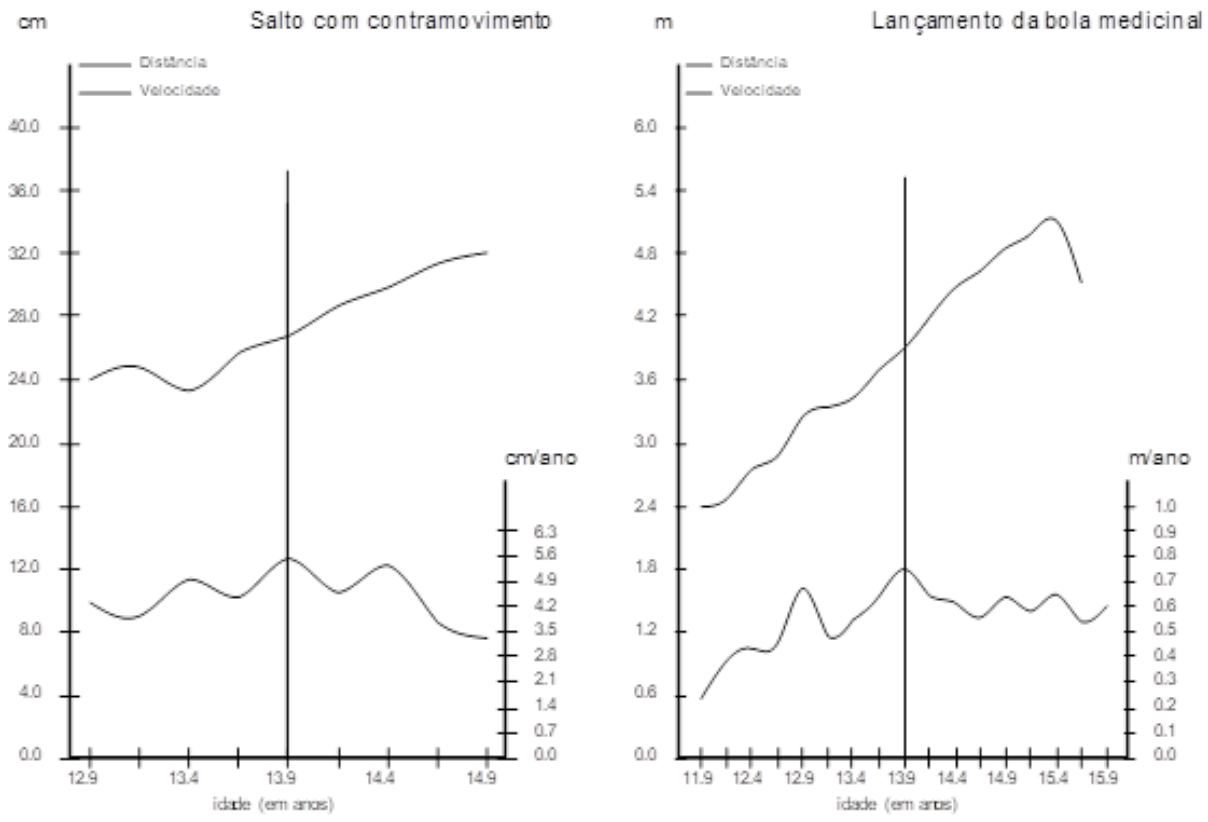

FIGURA 1. Curvas da distância e da velocidade do salto vertical com contramovimento e do lançamento sentado da bola medicinal

Velocidade de corrida

Apesar de não ser muito evidente o comportamento da trajetória média na curva da distância do teste de sprint 20m (FIGURA 2), os resultados revelam uma melhoria no desempenho. A curva da velocidade (FIGURA 2) mostra que o pico do desenvolvimento nesta prova ocorreu aos 13.4 anos de idade (i.e., 6 meses antes da iPVA) (intensidade $=0.40 \mathrm{~m} \cdot \mathrm{s}^{-1} \cdot \mathrm{ano}^{-1}$ ).

Face à escassez de estudos similares com jovens basquetebolistas, vemo-nos uma vez mais "obrigados" a comparar estes resultados com os reportados por Philippaerts et al. (2006) e Yagüe e De La Fuente (1998). Enquanto que no trabalho com futebolistas belgas os autores identificaram um pico na prova de sprint $30 \mathrm{~m}$ alcançado no momento em que ocorre o PVA (intensidade $=0.40 \mathrm{~s}^{\cdot} \mathrm{ano}^{-1}$ ) (Philippaerts et al., 2006), já no estudo com espanhóis foram identificados, nos rapazes, dois picos no teste sprint 40m: o primeiro, 16 meses antes do PVA (intensidade $=0.60 \mathrm{~s}^{\cdot} \mathrm{ano}^{-1}$ ) e o segundo 12 meses após o PVA (intensidade $\left.=0.56 \mathrm{~s} \cdot \mathrm{ano}^{-1}\right)($ Yagüe \& De La Fuente, 1998). Contudo, tais resultados causam alguma "estranheza", dado que a unidade de medida utilizada em ambos os estudos foi se- gundos. Sabendo-se que a melhoria do desempenho nestas e noutras quaisquer provas de velocidade ocorre sempre que os sujeitos demoram menos tempo a percorrer a distância (i.e., menor tempo significa mais velocidade e por consequência melhor desempenho), fica a dúvida se no caso dos futebolistas belgas e espanhóis não-atletas o pico não terá ocorrido 12 antes do PVA (intensidade $=-0.60 \mathrm{~s}^{\cdot} \cdot \mathrm{ano}^{-1}$ ) e 4 ou 16 meses após o PVA (intensidades $=0.34$ e $0.30 \mathrm{~s}^{\prime} \cdot \mathrm{ano}^{-1}$ ), respetivamente. Por outro lado, as distintas unidades de medida utilizadas nos diferentes estudos impossibilitam o contraste entre as intensidades dos picos alcançados pelos basquetebolistas, futebolistas e espanhóis não-atletas.

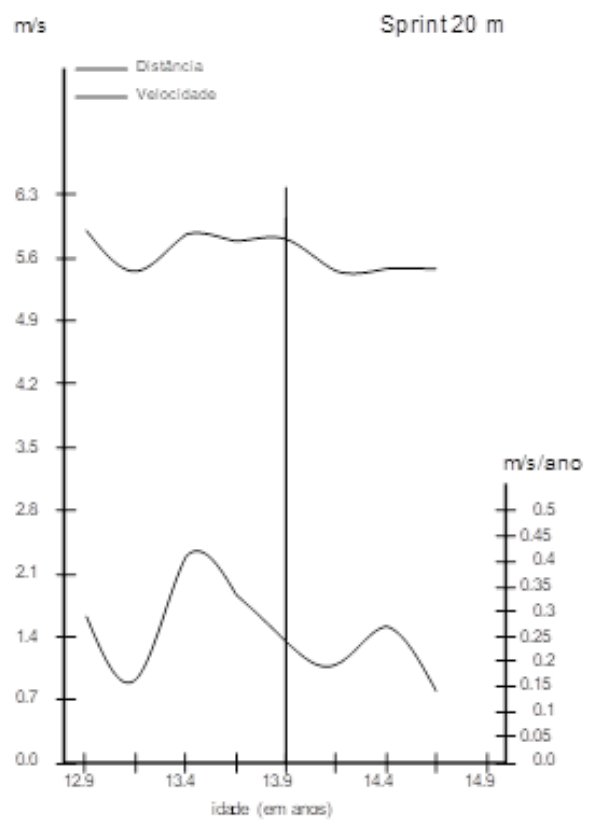

FIGURA 2. Curvas da distância e da velocidade do sprint $20 \mathrm{~m}$

Agilidade

Relativamente à curva da distância da prova de agilidade (FIGURA 3), e em conformidade com a prova anterior, os jovens basquetebolistas melhoraram o seu desempenho. Todavia, uma análise mais cuidada da curva revela uma melhoria sistemática, aproximadamente, dos 12.9 aos 13.4 anos de idade, seguida de uma ligeira estagnação/declínio do desempenho até aos 15.0 anos de idade. Por outro lado, a curva da velocidade (FIGURA 3) mostra um pico do desempenho no T-test aos 13.4 anos de idade, isto é, seis meses antes do PVA (intensidade $\left.=0.30 \mathrm{~m} \cdot \mathrm{s}-1 \cdot \mathrm{ano}^{-1}\right)$. 
Apesar de não ter sido possível encontrar qualquer estudo com o T-test na literatura disponível, importa referir que alguns trabalhos desta natureza utilizaram a prova de shuttle run para avaliar a agilidade. Por exemplo, e em contraste com os nossos resultados, Silva et al. (2019) e Philippaerts et al. (2006) identificaram picos no $10 \times 5$ m shuttle run 12 meses após o PVA em jovens não-atletas brasileiros e futebolistas belgas, respetivamente Por outro lado, Beunen et al. (1988), também com recurso ao $10 \times 5 \mathrm{~m}$ shuttle run, e Yagüe e De La Fuente (1998), utilizando o $4 \times 6 \mathrm{~m}$ shuttle run, reportaram picos 18 meses antes o PVA e 8 meses antes o PVA em jovens não-atletas belgas e espanhóis, respetivamente. Não obstante estes últimos resultados estarem aparentemente em linha com os nossos, a verdade é que, à semelhança da componente velocidade de corrida, fica a dúvida se os picos identificados por estes autores, em segundos, são de facto os momentos em que se verificou o melhor desempenho. Por exemplo, no caso do estudo com jovens espanhóis, Yagüe e De La Fuente (1998) reportaram, aos 8 meses antes do PVA, o pico de desenvolvimento com uma intensidade de $0.68 \mathrm{~s} \cdot \mathrm{ano}^{-1}$. Contudo, no momento do PVA e 4 meses após o PVA a intensidade foi de $0.16 \mathrm{~s} \cdot \mathrm{ano}^{-1}$. E se menos segundos representa melhor desempenho na prova, isto parece significar que o pico de desenvolvimento ocorreu após o PVA e não antes.

Quanto à intensidade dos picos, é interessante notar que os rapazes não-atletas brasileiros alcançaram uma intensidade mais elevada $\left(1.77 \mathrm{~m} \cdot \mathrm{s}-1 \cdot \mathrm{ano}^{-1}\right)$ do que os basquetebolistas $\left(0.30 \mathrm{~m} \cdot \mathrm{s}-1 \cdot \mathrm{ano}^{-1}\right)$. Contudo, tais diferenças devem-se muito provavelmente às especificidades das amostras, bem como aos distintos protocolos utilizados para medir a agilidade dos indivíduos ( $10 \times 5 \mathrm{~m}$ shuttle run vs. T-test).

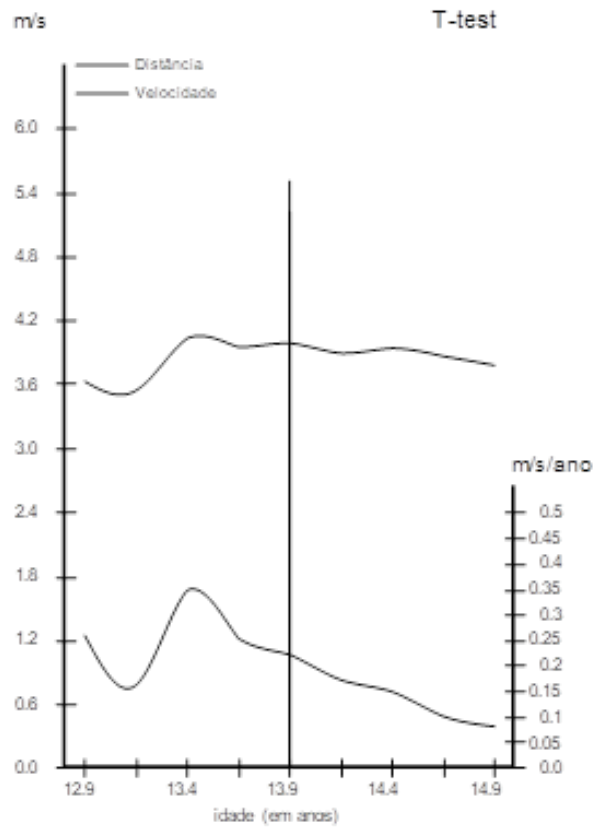

FIGURA 3. Curvas da distância e da velocidade do T-test
Performance aeróbia

À semelhança das anteriores componentes do desempenho motor, também a curva da distância do Yo-Yo Intermittent Recovery Test - Level 1 (Yo-Yo IR1) (FIGURA 4) mostra uma clara tendência de melhoria ao longo da idade, mais especificamente, dos 12.9 aos 14.9 anos. No que diz respeito à curva da velocidade (FIGURA 4), o pico foi atingido aos 13.9 anos de idade, isto é, coincidente com a iPVA (intensidade $=590.30 \mathrm{~m} \mathrm{ano}^{-1}$ ).

Coincidente com os nossos resultados, também Philippaerts et al. (2006) identificaram um pico da performance aeróbica coincidente com o PVA em jovens futebolistas belgas, ainda que o teste utilizado tenha sido o endurance shuttle run. Por outro lado, Silva et al. (2019) reportaram um pico na corrida de 12 minutos seis meses antes do PVA em rapazes brasileiros, ao passo que Yagüe e De La Fuente (1998) mostraram um pico na corrida de 6 minutos 8 meses após o PVA em rapazes espanhóis. Mais uma vez, a especificidade das amostras e os diferentes protocolos utilizados para avaliar a performance aeróbia podem justificar a discrepância observada. Aliás, tal facto pode também ter contribuído para as diferentes intensidades dos picos identificados (basquetebolistas: intensidade $=$ $590.30 \mathrm{~m}^{-a_{n} o^{-1}}$; futebolistas: intensidade $=1.50 \mathrm{~m} \mathrm{ano}^{-1}$; rapazes brasileiros: intensidade $515.07 \mathrm{~m}^{\prime} \mathrm{ano}^{-1}$; rapazes espanhóis: intensidade $=140.00 \mathrm{~m}^{\prime}$ ano $^{-1}$.

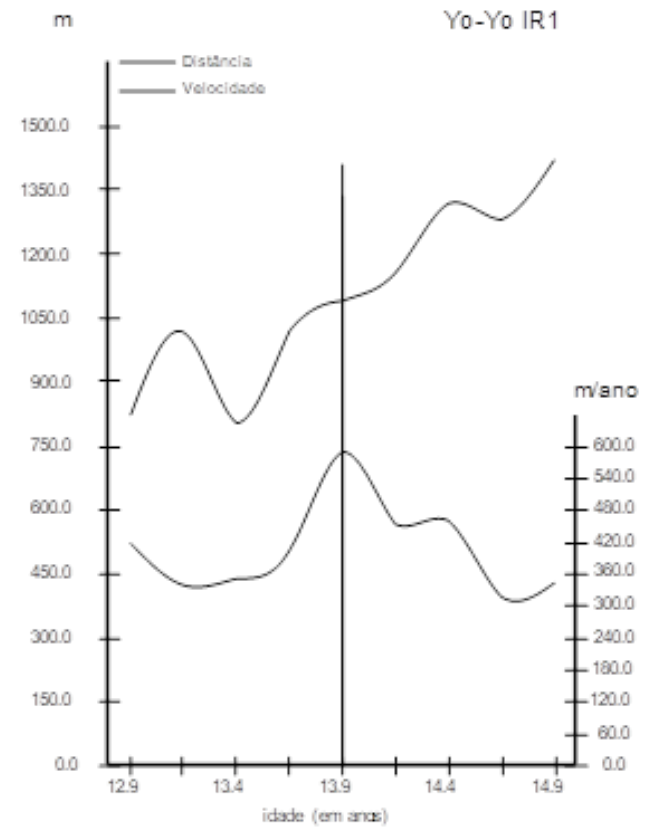

FIGURA 4. Curvas da distância e da velocidade do Yo-Yo IR 
CONCLUSÕES

Em conclusão, os picos de desenvolvimento das diferentes componentes do desempenho motor em estudo foram coincidentes com a iPVA (salto com contramovimento, lançamento sentado da bola medicinal e Yo-Yo IR1) ou ocorreram 6 meses antes do PVA (sprint $20 \mathrm{~m}$ e T-test). Estes resultados, similares aos reportados por Philippaerts et al. (2006) sugerem que os jovens atletas alcançam picos de desenvolvimento do desempenho motor relativamente mais cedo do que os seus pares não-atletas. Adicionalmente, os ganhos máximos no desempenho motor de jovens atletas parecem estar, de certa forma, associados ao aumento da estatura. Por fim, os jovens basquetebolistas alcançaram intensidades dos picos mais elevadas na maioria das provas de desempenho, sugerindo que o treino sistemático e regular potencia o desenvolvimento dos níveis de força muscular, velocidade, agilidade e performance aeróbia em jovens jogadores de basquetebol.

\section{IMPLICAÇÕES PARA O TREINADOR}

1. Haverá períodos em que a resposta dos atletas ao treino e à competição é mais elevada? Aparentemente, sim. E com base nos resultados apresentados, o ano em que ocorre o PVA parece ser um momento em que o desenvolvimento do desempenho motor pode e deve ser maximizado. De acordo com Bornstein et al. (1989), estes períodos sensíveis, também denominados de "janelas de oportunidade", são momentos durante os quais um indivíduo está altamente sensível às influências ambientais. Portanto, se identificados com precisão, os períodos sensíveis podem representar momentos de prontidão máxima (Malina, 2008) Resta que os treinadores estejam atentos a estes momentos, já que parecem os mais indicados a implementação de treinos de condição física.

\section{DOMÍNIO DAS HABILIDADES ESPECÍFICAS}

\section{PERCETIVO-COGNITIVAS. DESEMPENHO NO JOGO.}

\section{INTRODUÇÃO}

Nos jogos desportivos coletivos, nomeadamente nos de invasão, jogar a um alto nível de desempenho significa escolher as ações certas nos momentos certos e realizá-las de forma eficiente e consistente durante toda a partida (Baker et al., 2003; Gréhaigne et al. 2001). Um dos aspetos que mais contribui para que, durante as competições, os jogadores façam esta "escolha certa e consistente" diz respeito ao seu nível de desenvolvimento técnico-tático, tendo em conta as componentes do desempenho desportivo. Estas compreendem não só elementos relacionados com a eficiência (técnica) e eficácia (resultado) dos movimentos, mas também com a tomada de decisão e execução de habilidades e ações de apoio (Oslin et al., 1998).
Segundo Bunker e Thorpe (1983), o processo de tomada de decisão que precede a execução motora é um aspeto particular dos jogos desportivos. Por essa razão, diversos investigadores têm focado muita da sua atenção no estudo das tomadas de decisão dos jogadores em situação de jogo (McPherson \& French, 1991; Turner et al., 1992). Na verdade, a tomada de decisão tem um papel fundamental no desempenho desportivo, pois corresponde à seleção do modo mais correto de agir em função da experiência pessoal e das circunstâncias do jogo. Como consequência da eficiência das ações e das tomadas de decisão mais apropriadas é possível obter um resultado que se designa por eficácia no desempenho de cada uma das ações técnico-táticas que o jogo comporta. Ou seja, a eficácia é o resultado da execução de uma ação motora de acordo com as exigências e constrangimentos específicos do jogo num determinado momento específico (Oslin et al., 1998).

A partir das investigações do tipo novice-expert tem sido demonstrado que à medida que o nível de execução do expert melhora em relação ao novato, o mesmo acontece à qualidade e quantidade de informação do conhecimento de base (French et al., 1996; Gallagher et al., 1996; Griffin et al., 2001; McPherson, 1999). Isto deve-se ao facto de os experts serem capazes de interpretar melhor a informação simples e/ou complexa que recebem do meio envolvente, o que lhes permite uma formulação mais apropriada do plano de ação a executar (Tavares, 1995; Thomas et al., 2001; Williams et al., 2010).

Um dos propósitos do Projeto INEX foi analisar o desempenho no jogo, sob o ponto de vista técnico-tático, de jovens basquetebolistas em contexto de jogo $3 \times 3$ em meio-campo Foram avaliados os seguintes comportamentos: (a) tomada de decisão; (b) execução motora; e (c) resultado da ação. Para a consecução deste propósito recorreu-se ao Game Assessment Performance Instrument (GPAI, Oslin et al., 1998). Este instrumento, amplamente utilizado na investigação, permitiu (a) avaliar os comportamentos e o desempenho de um jogador em situações de jogo, (b) analisar a sua capacidade de selecionar e aplicar as habilidades adequadas num determinado contexto, bem como (c) analisar o jogo na sua totalidade. De facto, com o advento do GPAI, os investigadores e treinadores que se dedicam à avaliação e análise do jogo passaram a contar com um instrumento que possibilita estudar indicadores do desempenho efetivo no jogo, contemplando não apenas a execução contextualizada das habilidades, mas também a tomada de decisão, o posicionamento no campo e as ações sem bola no ataque e na defesa.

METODOLOGIA

$\mathrm{Na}$ análise transversal, a amostra compreendeu 178 jovens basquetebolistas do sexo masculino, com idades entre 11-15 anos, distribuídos por cinco coortes de idade $(11,12,13,14$ 15 anos), pertencentes a 19 clubes da Associação de Basquetebol do Porto. Destes 178 basquetebolistas, apenas 120 foram utilizados na análise longitudinal. 
Em ambas as análises, todos os jogadores participaram num jogo reduzido de $3 \times 3$, em meio-campo, com a duração de 10 minutos (correspondente a um quarto do jogo de basquetebol) e o seu desempenho foi avaliado recorrendo a uma grelha de observação constituída da seguinte forma:

1. Dez categorias: receção/enquadramento, passe, drible, lançamento, movimentos sem bola, ressalto ofensivo, ressalto defensivo, marcação ao jogador com bola, marcação ao jogador sem bola, ajuda defensiva;

2. Três subcategorias (por categoria): tomada de decisão, execução motora e resultado da ação;

3. Comportamentos apropriados e inapropriados em cada subcategoria.

Posteriormente, foram calculados três índices relativos: tomada de decisão, execução motora e resultado da ação. 0 índice da tomada de decisão (ITD), o índice da execução motora (IEM) e o índice do resultado da ação (IRA) foram calculados através da seguinte fórmula:

número de respostas apropriadas/(número de respostas apropriadas + número de respostas inapropriadas)

A partir destes três índices calculou-se o valor do desempenho individual no jogo recorrendo à seguinte fórmula:

\section{desempenho no jogo $=(I T D+$ IEM + IRA $) / 3$}

Foi utilizada, também, uma técnica estatística de agrupamento de sujeitos por forma a dividir a amostra em três subgrupos com base na experiência acumulada de treino: baixa experiência ( $n=61,1-4$ anos de prática), moderada experiência ( $n=79,5-7$ anos de prática) e elevada experiência ( $n=38,8-11$ anos de prática).

ANÁLISE E INTERPRETAÇÃO DOS RESULTADOS

Informação transversal: Contraste por coortes de idade

Tomada de decisão, execução motora e resultado da ação

No início do Projeto INEX, isto é, no momento da primeira avaliação (baseline), e como esperado, os basquetebolistas mais velhos apresentaram valores superiores nos três índices de desempenho (QUADRO 1), verificando-se um aumento gradual nos valores das médias ao longo das cinco coortes de idade (com exceção do índice da tomada de decisão na coorte 2). De realçar ainda que o índice da tomada de decisão apresenta sempre, comparativamente ao índice da execução motora e ao índice do resultado da ação, valores médios mais elevados nas respetivas cinco coortes. por coorte, no baseline

\begin{tabular}{|c|c|c|c|c|c|c|c|}
\hline \multirow{3}{*}{ ÍNDICES } & $\begin{array}{l}\text { COORTE } 1 \\
\text { (C1) }\end{array}$ & $\begin{array}{c}\text { COORTE } 2 \\
\text { (C2) }\end{array}$ & $\begin{array}{c}\text { COORTE } 3 \\
\text { (C3) }\end{array}$ & $\begin{array}{l}\text { COORTE } 4 \\
\text { (C4) }\end{array}$ & $\begin{array}{c}\text { COORTE } 5 \\
\text { (C5) }\end{array}$ & \multirow{3}{*}{$F\left(\mathrm{pn}^{2}\right)$} & \multirow{3}{*}{ CONTRASTE } \\
\hline & $(n=18)$ & $(n=45)$ & $(n=37)$ & $(n=32)$ & $(n=46)$ & & \\
\hline & $M \pm D P$ & $M \pm D P$ & $M \pm D P$ & $M \pm D P$ & $M \pm D P$ & & \\
\hline Tomada de decisão & $0.53 \pm 0.16$ & $0.50 \pm 0.18$ & $0.56 \pm 0.19$ & $0.63 \pm 0.15$ & $0.69 \pm 0.18$ & $7.95^{* * *}(.16)$ & $\begin{array}{c}\mathrm{C} 4>\mathrm{C} 2 ; \\
\mathrm{C} 5>\mathrm{C} 3, \mathrm{C} 2, \mathrm{C} 1 \\
\end{array}$ \\
\hline Execução motora & $0.40 \pm 0.22$ & $0.43 \pm 0.21$ & $0.48 \pm 0.21$ & $0.55 \pm 0.18$ & $0.65 \pm 0.20$ & $9.09 * \star(17)$ & $\mathrm{C} 5>\mathrm{C} 3, \mathrm{C} 2, \mathrm{Cl}$ \\
\hline Resultado da ação & $0.40 \pm 0.14$ & $0.45 \pm 0.17$ & $0.51 \pm 0.17$ & $0.56 \pm 0.14$ & $0.62 \pm 0.16$ & $9.50^{\star * \star}(.18)$ & $\begin{array}{c}\mathrm{C} 4>\mathrm{C} 2, \mathrm{Cl} ; \\
\mathrm{C} 5>\mathrm{C} 3, \mathrm{C} 2, \mathrm{Cl}\end{array}$ \\
\hline
\end{tabular}

Desempenho no jogo

quadro 2 apresenta o valor de desempenho no jogo dos basquetebolistas das cinco coortes de idade. Os resultados revelaram um aumento gradual e consistente dos valores médios deste indicador nos jogadores ao longo das diferentes coortes. Ou seja, no início do estudo, os atletas mais velhos apresentaram melhores valores deste indicador comparativamente aos mais novos.

QUADRO 2. Resultados dos basquetebolistas desempenho no jogo, por coorte, no baseline

\begin{tabular}{lccccccc} 
& $\begin{array}{c}\mathrm{COORTE} 1 \\
(\mathrm{C} 1)\end{array}$ & $\begin{array}{c}\mathrm{COORTE} 2 \\
(\mathrm{C} 2)\end{array}$ & $\begin{array}{c}\mathrm{COORTE} 3 \\
(\mathrm{C} 3)\end{array}$ & $\begin{array}{c}\mathrm{COORTE} 4 \\
(\mathrm{C} 4)\end{array}$ & $\begin{array}{c}\mathrm{COORTE} 5 \\
(\mathrm{C} 5)\end{array}$ & \\
\cline { 2 - 6 } & $(n=18)$ & $(n=45)$ & $(n=37)$ & $(n=32)$ & $(n=46)$ & $F\left(\mathrm{pn}^{2}\right)$ & CONTRASTE \\
\cline { 2 - 6 } & $M \pm D P$ & $M \pm D P$ & $M \pm D P$ & $M \pm D P$ & $M \pm D P$ & & \\
\hline
\end{tabular}
\begin{tabular}{cccccccc}
\hline Desempenhono jogo & $0.44 \pm 0.17$ & $0.46 \pm 0.18$ & $0.51 \pm 0.18$ & $0.58 \pm 0.14$ & $0.65 \pm 0.17$ & $9.52^{* * *(18)}$ & $\begin{array}{c}C 4>C 2 ; \\
C 5>C 3, \mathrm{C} 2, \mathrm{Cl} 1\end{array}$ \\
\hline
\end{tabular}

Ações (apropriadas e inapropriadas)

Os resultados do baseline mostraram que os jovens basquetebolistas das coortes 4 e 5 realizaram um número significativamente maior de ações apropriadas, contrastando com o maior número de ações inapropriadas dos seus pares das coortes 1 e 2 (QUADRO 3). Grosso modo, os resultados evidenciam que os jogadores mais velhos deram respostas mais apropriadas às exigências do jogo reduzido, ao passo que os jogadores mais novos apresentaram um desempenho no jogo de baixa eficácia. 


\begin{tabular}{|c|c|c|c|c|c|c|c|}
\hline \multirow{3}{*}{ ÍNDICES } & $\begin{array}{c}\text { COORTE } 1 \\
\text { (C1) }\end{array}$ & $\begin{array}{c}\text { COORTE } 2 \\
\text { (C2) }\end{array}$ & $\begin{array}{c}\text { COORTE } 3 \\
\text { (C3) }\end{array}$ & $\begin{array}{c}\text { COORTE } 4 \\
\text { (C4) }\end{array}$ & $\begin{array}{l}\text { COORTE } 5 \\
\text { (C5) }\end{array}$ & \multirow{3}{*}{$F\left(\mathrm{pn}^{2}\right)$} & \multirow{3}{*}{ CONTRASTE } \\
\hline & $(n=18)$ & $(n=45)$ & $(n=37)$ & $(n=32)$ & $(n=46)$ & & \\
\hline & $M \pm D P$ & $M \pm D P$ & $M \pm D P$ & $M \pm D P$ & $M \pm D P$ & & \\
\hline Apropriadas & $42.72 \pm 19.08$ & $46.04 \pm 21.13$ & $55.51 \pm 23.25$ & $65.06 \pm 24.73$ & $77.35 \pm 29.59$ & $12.28^{* * *}(.22)$ & $\begin{array}{c}\mathrm{C} 4>\mathrm{C} 2_{2} \mathrm{Cl} ; \\
\mathrm{C} 5>\mathrm{C} 3, \mathrm{C} 2, \mathrm{Cl}\end{array}$ \\
\hline Inapropriadas & $52.33 \pm 18.64$ & $52.53 \pm 21.75$ & $49.86 \pm 17.70$ & $45.28 \pm 16.42$ & $38.37 \pm 18.07$ & $4.05 * \star(.09)$ & $\mathrm{C} 5>\mathrm{C} 3, \mathrm{C} 2$ \\
\hline Total & $95.06 \pm 20.10$ & $98.58 \pm 23.17$ & $105.38 \pm 17.61$ & $110.34 \pm 24.38$ & $115.72 \pm 26.04$ & $4.58^{\star \star}(.10)$ & $\mathrm{C} 5>\mathrm{C} 2, \mathrm{Cl}$ \\
\hline
\end{tabular}

Índices da tomada de decisão por categoria

0 quadro 4 apresenta os resultados do contraste entre os basquetebolistas das cinco coortes de idade nas dez categorias do ITD. Genericamente, no início do Projeto INEX, os jogadores mais velhos apresentaram valores significativamente superiores quando comparados com os seus pares mais novos em seis das dez categorias (drible, lançamento, ressalto ofensivo, ressalto defensivo, marcação ao jogador com bola e marcação ao jogador sem bola). De notar que os atletas das coortes 4 e 5 (mais velhos) são os que apresentam um índice da tomada de decisão mais elevado. Por fim, destacam-se os baixos valores médios da tomada de decisão no drible, contrastando com os elevados valores da ajuda defensiva nos basquetebolistas das cinco coortes.

QUADRO 4. Resultados dos basquetebolistas nos índices de tomada de decisão de cada categoria, por coorte, no baseline

\begin{tabular}{|c|c|c|c|c|c|c|c|}
\hline \multirow{3}{*}{ ÍNDICES } & $\begin{array}{l}\text { COORTE } 1 \\
(\mathrm{C} 1)\end{array}$ & $\begin{array}{c}\text { COORTE } 2 \\
(\mathrm{C} 2)\end{array}$ & $\begin{array}{c}\text { COORTE } 3 \\
(\mathrm{C} 3)\end{array}$ & $\begin{array}{c}\text { COORTE } 4 \\
(\mathrm{C} 4)\end{array}$ & $\begin{array}{c}\text { COORTE } 5 \\
(\mathrm{C} 5) \\
\end{array}$ & \multirow{3}{*}{$F\left(\mathrm{pn}^{2}\right)$} & \multirow{3}{*}{ CONTRASTE } \\
\hline & $(n=18)$ & $(n=45)$ & $(n=37)$ & $(n=32)$ & $(n=46)$ & & \\
\hline & $M \pm D P$ & $M \pm D P$ & $M \pm D P$ & $M \pm D P$ & $M \pm D P$ & & \\
\hline Receção/paragem & $0.76 \pm 0.25$ & $0.64 \pm 0.32$ & $0.69 \pm 0.29$ & $0.73 \pm 0.22$ & $0.75 \pm 0.25$ & $1.27 \mathrm{~ns}(.03)$ & --- \\
\hline Passe & $0.87 \pm 0.18$ & $0.79 \pm 0.21$ & $0.81 \pm 0.23$ & $0.82 \pm 0.22$ & $0.89 \pm 0.18$ & $1.64 n s(.04)$ & --- \\
\hline Drible & $0.49 \pm 0.32$ & $0.29 \pm 0.24$ & $0.23 \pm 0.22$ & $0.34 \pm 0.28$ & $0.52 \pm 0.31$ & $7.74^{\star \star \star}(.16)$ & $\mathrm{C} 5>\mathrm{C} 4, \mathrm{C} 3, \mathrm{C} 2$ \\
\hline Lançamento & $0.61 \pm 0.24$ & $0.62 \pm 0.27$ & $0.59 \pm 0.26$ & $0.72 \pm 0.20$ & $0.75 \pm 0.23$ & $3.43^{*}(.08)$ & $\mathrm{C} 5>\mathrm{C} 3$ \\
\hline $\begin{array}{l}\text { Movimento sem } \\
\text { bola }\end{array}$ & $0.61 \pm 0.35$ & $0.58 \pm 0.33$ & $0.62 \pm 0.33$ & $0.64 \pm 0.32$ & $0.64 \pm 0.34$ & $0.31 n s(.01)$ & -- \\
\hline Ressalto ofensivo & $0.39 \pm 0.42$ & $0.28 \pm 0.31$ & $0.44 \pm 0.36$ & $0.42 \pm 0.34$ & $0.54 \pm 0.37$ & $2.84^{*}(.07)$ & $\mathrm{C} 5>\mathrm{C} 2$ \\
\hline Ressalto defensivo & $0.41 \pm 0.37$ & $0.42 \pm 0.34$ & $0.55 \pm 0.33$ & $0.59 \pm 0.41$ & $0.66 \pm 0.32$ & $3.15^{*}(.07)$ & $\mathrm{C} 5>\mathrm{C} 2$ \\
\hline
\end{tabular}

\begin{tabular}{|c|c|c|c|c|c|c|c|}
\hline \multirow{3}{*}{ ÍNDICES } & $\begin{array}{c}\text { COORTE } 1 \\
\text { (C1) }\end{array}$ & $\begin{array}{c}\text { COORTE } 2 \\
(\mathrm{C} 2)\end{array}$ & $\begin{array}{c}\text { COORTE } 3 \\
(\mathrm{C} 3)\end{array}$ & $\begin{array}{c}\text { COORTE } 4 \\
\text { (C4) }\end{array}$ & $\begin{array}{c}\text { COORTE } 5 \\
\text { (C5) }\end{array}$ & \multirow{3}{*}{$F\left(\mathrm{pn}^{2}\right)$} & \multirow{3}{*}{ CONTRASTE } \\
\hline & $(n=18)$ & $(n=45)$ & $(n=37)$ & $(n=32)$ & $(n=46)$ & & \\
\hline & $M \pm D P$ & $M \pm D P$ & $M \pm D P$ & $M \pm D P$ & $M \pm D P$ & & \\
\hline $\begin{array}{l}\text { Marcação jogador } \\
\text { com bola }\end{array}$ & $0.44 \pm 0.26$ & $0.45 \pm 0.33$ & $0.57 \pm 0.30$ & $0.68 \pm 0.20$ & $0.70 \pm 0.26$ & $6.50^{\star \star \star}(.13)$ & $\mathrm{C} 5, \mathrm{C} 4>\mathrm{C} 2, \mathrm{Cl}$ \\
\hline $\begin{array}{l}\text { Marcação jogador } \\
\text { sem bola }\end{array}$ & $0.21 \pm 0.34$ & $0.30 \pm 0.40$ & $0.44 \pm 0.38$ & $0.67 \pm 0.37$ & $0.70 \pm 0.39$ & $\left.9.85^{* * \times} .19\right)$ & $\begin{array}{c}\mathrm{C} 4>\mathrm{C} 2, \mathrm{C} 1 ; \\
\mathrm{C} 5>\mathrm{C} 3, \mathrm{C} 2, \mathrm{Cl}\end{array}$ \\
\hline Ajuda defensiva & $0.73 \pm 0.47$ & $0.72 \pm 0.42$ & $0.82 \pm 0.37$ & $0.86 \pm 0.33$ & $0.89 \pm 0.29$ & $0.83 n s(.04)$ & -- \\
\hline
\end{tabular}

Índices da execução motora por categoria

Os valores dos basquetebolistas das cinco coortes nas diferentes categorias do índice da execução motora apresentam-se no quadro 5 . Os resultados mostram uma tendência semelhante à anterior, isto é, no início do estudo os jogadores mais velhos (coortes 4 e 5) são os que apresentaram, em média, os melhores valores de execução motora. De notar ainda os baixos valores médios da categoria lançamento para os atletas das quatro coortes de idade mais baixas.

QUADRO 5. Resultados dos basquetebolistas nos índices de execução motora de cada categoria, por coorte, no baseline

\begin{tabular}{|c|c|c|c|c|c|c|c|}
\hline \multirow{3}{*}{ ÍNDICES } & $\begin{array}{c}\text { COORTE } 1 \\
\text { (C1) }\end{array}$ & $\begin{array}{c}\text { COORTE } 2 \\
(\mathrm{C} 2)\end{array}$ & $\begin{array}{c}\text { COORTE } 3 \\
(\mathrm{C} 3)\end{array}$ & $\begin{array}{c}\text { COORTE } 4 \\
\text { (C4) }\end{array}$ & $\begin{array}{c}\text { COORTE } 5 \\
\text { (C5) }\end{array}$ & \multirow{3}{*}{$F\left(\mathrm{pn}^{2}\right)$} & \multirow{3}{*}{ CONTRASTE } \\
\hline & $(n=18)$ & $(n=45)$ & $(n=37)$ & $(n=32)$ & $(n=46)$ & & \\
\hline & $M \pm D P$ & $M \pm D P$ & $M \pm D P$ & $M \pm D P$ & $M \pm D P$ & & \\
\hline Receção/paragem & $0.55 \pm 0.35$ & $0.45 \pm 0.34$ & $0.45 \pm 0.33$ & $0.60 \pm 0.33$ & $0.63 \pm 0.29$ & $2.56^{*}(.06)$ & --- \\
\hline Passe & $0.62 \pm 0.38$ & $0.52 \pm 0.30$ & $0.57 \pm 0.32$ & $0.66 \pm 0.30$ & $0.79 \pm 0.23$ & $5.14^{\star \star \star}(.11)$ & $\mathrm{C} 5>\mathrm{C} 3, \mathrm{C} 2$ \\
\hline Drible & $0.68 \pm 0.34$ & $0.54 \pm 0.35$ & $0.60 \pm 0.34$ & $0.69 \pm 0.25$ & $0.75 \pm 0.26$ & $2.98^{*}(.07)$ & $\mathrm{C} 5>\mathrm{C} 2$ \\
\hline Lançamento & $0.38 \pm 0.22$ & $0.41 \pm 0.29$ & $0.36 \pm 0.24$ & $0.45 \pm 0.29$ & $0.58 \pm 0.26$ & $4.11^{\star *}(.09)$ & $\mathrm{C} 5>\mathrm{C} 3, \mathrm{C} 2$ \\
\hline $\begin{array}{l}\text { Movimento sem } \\
\text { bola }\end{array}$ & $0.33 \pm 0.34$ & $0.37 \pm 0.35$ & $0.44 \pm 0.35$ & $0.50 \pm 0.41$ & $0.64 \pm 0.36$ & $3.98^{* \star}(.09)$ & $\mathrm{C} 5>\mathrm{C} 2, \mathrm{Cl}$ \\
\hline Ressalto ofensivo & $0.81 \pm 0.37$ & $0.72 \pm 0.37$ & $0.85 \pm 0.32$ & $0.68 \pm 0.48$ & $0.81 \pm 0.31$ & $0.84 \mathrm{~ns}(.03)$ & --- \\
\hline Ressalto defensivo & $0.18 \pm 0.35$ & $0.44 \pm 0.39$ & $0.41 \pm 0.37$ & $0.43 \pm 0.35$ & $0.70 \pm 0.34$ & $6.91^{* \star \star}(.16)$ & $\begin{array}{c}\mathrm{C} 5<\mathrm{C} 4, \mathrm{C} 3, \\
\mathrm{C2,C1}\end{array}$ \\
\hline $\begin{array}{l}\text { Marcação jogador } \\
\text { com bola }\end{array}$ & $0.24 \pm 0.25$ & $0.34 \pm 0.32$ & $0.42 \pm 0.30$ & $0.50 \pm 0.23$ & $0.56 \pm 0.28$ & $5.93^{* \star \star}(.12)$ & $\begin{array}{c}\mathrm{C} 4>\mathrm{Cl} ; \\
\mathrm{C} 5>\mathrm{C} 2, \mathrm{Cl} \\
\end{array}$ \\
\hline $\begin{array}{l}\text { Marcação jogador } \\
\text { sem bola }\end{array}$ & $0.21 \pm 0.35$ & $0.24 \pm 0.37$ & $0.41 \pm 0.38$ & $0.64 \pm 0.36$ & $0.66 \pm 0.40$ & $10.22^{1 \times * x} .(20)$ & $\begin{array}{c}\mathrm{C} 4>\mathrm{C} 2, \mathrm{Cl} i_{i} \\
\mathrm{C} 5>\mathrm{C} 3, \mathrm{C} 2, \mathrm{C} 1 \\
\end{array}$ \\
\hline Ajuda defensiva & $0.50 \pm 0.46$ & $0.78 \pm 0.39$ & $0.81 \pm 0.38$ & $0.87 \pm 0.33$ & $0.79 \pm 0.37$ & $1.37 n s(.07)$ & --- \\
\hline
\end{tabular}


Índices do resultado da ação por categoria

0 quadro 6 mostra os valores médios dos basquetebolistas das cinco coortes nas diferentes categorias do índice do resultado da ação. Similarmente aos índices acima mencionados, no baseline, os jogadores mais velhos foram mais eficazes do ponto de vista técnico comparativamente com os seus pares mais novos. Esta tendência é fortemente acentuada para a maioria das categorias no contraste entre os atletas das coortes 4 e 5 e os das coortes 1,2 e 3.

QUADRO 6. Resultados dos basquetebolistas nos índices de resultado da ação de cada categoria, por coorte, no baseline

\begin{tabular}{|c|c|c|c|c|c|c|c|}
\hline \multirow{3}{*}{ ÍNDICES } & $\begin{array}{c}\text { COORTE } 1 \\
(\mathrm{C} 1)\end{array}$ & $\begin{array}{c}\text { COORTE } 2 \\
(\mathrm{C} 2)\end{array}$ & $\begin{array}{c}\text { COORTE } 3 \\
(\mathrm{C} 3)\end{array}$ & $\begin{array}{c}\text { COORTE } 4 \\
(\mathrm{C} 4)\end{array}$ & $\begin{array}{c}\text { COORTE } 5 \\
\text { (C5) }\end{array}$ & \multirow{3}{*}{$F\left(\mathrm{pn}^{2}\right)$} & \multirow{3}{*}{ CONTRASTE } \\
\hline & $(n=18)$ & $(n=45)$ & $(n=37)$ & $(n=32)$ & $(n=46)$ & & \\
\hline & $M \pm D P$ & $M \pm D P$ & $M \pm D P$ & $M \pm D P$ & $M \pm D P$ & & \\
\hline Receção/paragem & $0.30 \pm 0.29$ & $0.23 \pm 0.24$ & $0.25 \pm 0.25$ & $0.32 \pm 0.34$ & $0.52 \pm 0.33$ & $6.96^{* \star *}(.14)$ & $\mathrm{C} 5>\mathrm{C} 4, \mathrm{C} 3, \mathrm{C} 2$ \\
\hline Passe & $0.68 \pm 0.35$ & $0.66 \pm 0.27$ & $0.70 \pm 0.27$ & $0.81 \pm 0.22$ & $0.88 \pm 0.18$ & $5.31^{\star \star \star} .(12)$ & $\mathrm{C} 5>\mathrm{C} 3, \mathrm{C} 2, \mathrm{Cl}$ \\
\hline Drible & $0.83 \pm 0.22$ & $0.70 \pm 0.30$ & $0.73 \pm 0.28$ & $0.80 \pm 0.22$ & $0.81 \pm 0.26$ & $1.45 n s(.03)$ & --- \\
\hline Lançamento & $0.29 \pm 0.19$ & $0.35 \pm 0.30$ & $0.31 \pm 0.25$ & $0.34 \pm 0.23$ & $0.40 \pm 0.26$ & $1.11(0.03)$ & --- \\
\hline $\begin{array}{l}\text { Movimento sem } \\
\text { bola }\end{array}$ & $0.62 \pm 0.33$ & $0.64 \pm 0.37$ & $0.74 \pm 0.27$ & $0.82 \pm 0.25$ & $0.82 \pm 0.28$ & $3.11^{*}(.07)$ & --- \\
\hline Ressalto ofensivo & $0.65 \pm 0.44$ & $0.72 \pm 0.41$ & $0.80 \pm 0.36$ & $0.57 \pm 0.45$ & $0.71 \pm 0.38$ & $1.01 n s(.04)$ & --- \\
\hline Ressalto defensivo & $0.40 \pm 0.40$ & $0.54 \pm 0.41$ & $0.71 \pm 0.33$ & $0.61 \pm 0.36$ & $0.77 \pm 0.33$ & $3.88^{\star \star}(.10)$ & $\mathrm{C} 5>\mathrm{C} 2, \mathrm{Cl}$ \\
\hline $\begin{array}{l}\text { Marcação jogador } \\
\text { com bola }\end{array}$ & $0.23 \pm 0.22$ & $0.28 \pm 0.31$ & $0.36 \pm 0.27$ & $0.42 \pm 0.20$ & $0.49 \pm 0.27$ & $5.09^{\star \star \star}(.11)$ & $\mathrm{C} 5>\mathrm{C} 2, \mathrm{C} 1$ \\
\hline $\begin{array}{l}\text { Marcação jogador } \\
\text { sem bola }\end{array}$ & $0.15 \pm 0.31$ & $0.21 \pm 0.35$ & $0.35 \pm 0.36$ & $0.54 \pm 0.37$ & $0.59 \pm 0.39$ & $9.24^{\star * \star}(.18)$ & $\begin{array}{c}\mathrm{C} 4>\mathrm{C} 2, \mathrm{C} 1 ; \\
\mathrm{C} 5>\mathrm{C} 3, \mathrm{C} 2, \mathrm{C} 1 \\
\end{array}$ \\
\hline Ajuda defensiva & $0.38 \pm 0.44$ & $0.76 \pm 0.41$ & $0.55 \pm 0.50$ & $0.75 \pm 0.40$ & $0.61 \pm 0.44$ & $1.48 \mathrm{~ns}(.08)$ & --- \\
\hline
\end{tabular}

Lacunas identificadas nos fundamentos técnico-táticos que urge serem colmatadas

Para que o processo de desenvolvimento seja bem-sucedido, os jovens atletas devem aprender e executar diversos fundamentos técnico-táticos de forma que a sua resposta ao treino e à competição seja o mais elevada possível. Com base nos resultados apresentados, este ponto visa destacar alguns dos fundamentos menos conseguidos (i.e., pior desempenho) que, por serem cruciais para o sucesso no jogo, devem ser considerados pelos treinadores aquando da preparação das sessões de treino e planeamento das épocas desportivas.
1. De notar os baixos valores encontrados nos índice da execução motora (técnica) e índice do resultado da ação (eficácia) relativamente ao lançamento, aspeto comum aos basquetebolistas das cinco coortes de idades. Este resultado, vem realçar uma lacuna já anteriormente identificada no jogador português (i.e., as suas baixas percentagens de lançamento), sobretudo em confrontos internacionais.

2. De realçar os baixos valores das médias do índice da tomada de decisão no drible para os jogadores das cinco coortes. Esta utilização indiscriminada do drible (bola na mão, bola no chão) poderá diminuir bastante a ofensividade dos jogadores e evidencia uma baixa intencionalidade tática de saber quando driblar.

3. São também notórios os baixos valores médios nos ressaltos ofensivo e defensivo no índice da tomada de decisão, o que poderá significar alguma dificuldade em tomar a decisão sobre o ato de "ir ao ressalto", de disputar a bola em áreas muito congestionadas, com muita aglomeração de jogadores. Poderá corresponder também a uma fraca "agressividade mental" dos jovens basquetebolistas que optam com mais frequência pela "não disputa" do ressalto ofensivo.

4. A mesma tendência foi encontrada no índice da execução motora e no índice do resultado da ação em relação à marcação do jogador com bola e sem bola, principalmente nos basquetebolistas das coortes 1,2 e 3 . Tal facto poderá significar que estes atletas (mais novos) encontram-se, muito possivelmente, num processo inicial de formação onde os aspetos relacionados com o processo defensivo são menos treinados comparativamente com os aspetos ofensivos.

5. Uma nota final a propósito dos valores encontrados nos três índices (índice da tomada de decisão, índice da execução motora e índice do resultado da ação) na categoria ajuda defensiva. Contrariamente às duas categorias anteriores relativas à defesa individual, aqui os valores encontrados são elevados. No entanto, uma justificação para este resultado poderá ter a ver com o facto de nos jogos reduzidos o número de ações que exigiram um comportamento de ajuda ter sido diminuta e, como tal, só os basquetebolistas com mais competência nesta categoria realizaram esta ação com maior sucesso.

Informação transversal: Contraste por anos de experiência de treino Tomada de decisão, execução motora e resultado da ação

Os resultados apresentados no quadro 7 salientam a importância do fator experiência, neste caso traduzida em anos de treino, como um aspeto fundamental para o sucesso nas diversas componentes do desempenho no jogo. De facto, no início do estudo, os basquetebolistas com experiência elevada de treino apresentaram valores significativamente mais elevadas nos três índices em análise, comparativamente com os seus pares menos experientes. 


\begin{tabular}{|c|c|c|c|c|c|}
\hline \multirow{3}{*}{ ÍNDICES } & $\begin{array}{c}\text { BAIXA } \\
\text { EXPERIÊNCIA } \\
\text { BE) }\end{array}$ & $\begin{array}{c}\text { MODERADA } \\
\text { EXPERIÊNCIA } \\
\text { (ME) }\end{array}$ & $\begin{array}{c}\text { ELEVADA } \\
\text { EXPERIÊNCIA } \\
(\text { EE) }\end{array}$ & \multirow{3}{*}{$F\left(p n^{2}\right)$} & \multirow{3}{*}{ CONTRASTE } \\
\hline & $(n=61)$ & $(n=79)$ & $(n=38)$ & & \\
\hline & $M \pm D P$ & $M \pm D P$ & $M \pm D P$ & & \\
\hline Tomada de decisão & $0.53 \pm 0.19$ & $0.58 \pm 0.18$ & $0.69 \pm 0.16$ & $9.02^{* * \star}(.09)$ & $\mathrm{EE}>\mathrm{ME}, \mathrm{BE}$ \\
\hline Execução motora & $0.44 \pm 0.22$ & $0.51 \pm 0.21$ & $0.64 \pm 0.19$ & $10.76^{\star \star \star}(.11)$ & $\mathrm{EE}>\mathrm{ME}, \mathrm{BE}$ \\
\hline Resultado da ação & $0.47 \pm 0.17$ & $0.52 \pm 0.17$ & $0.62 \pm 0.17$ & $10.10^{* \star x}(.10)$ & $\mathrm{EE}>\mathrm{ME}, \mathrm{BE}$ \\
\hline
\end{tabular}

\section{Desempenho no jogo}

O quadro 8 apresenta o valor de desempenho no jogo, no baseline, dos basquetebolistas com baixa, moderada e elevada experiência de treino. Os resultados mostraram uma tendência semelhante à encontrada aquando do contraste por coortes de idade, isto é, os jogadores com experiência elevada de treino apresentaram valores de desempenho no jogo significativamente mais elevados do que os seus pares com níveis de experiência mais baixos.

QUADRO 8. Resultados dos basquetebolistas nos índices de tomada de decisão, de execução motora e resultado da ação por niveis de experiência de treino, no baseline

\begin{tabular}{|c|c|c|c|c|c|}
\hline \multirow{3}{*}{ ÍNDICES } & $\begin{array}{c}\text { BAIXA } \\
\text { EXPERIÊNCIA } \\
(\mathrm{BE}) \\
\end{array}$ & $\begin{array}{l}\text { MODERADA } \\
\text { EXPERIÊNCIA } \\
\text { (ME) }\end{array}$ & $\begin{array}{c}\text { ELEVADA } \\
\text { EXPERIÊNCIA } \\
(\text { EE) } \\
\end{array}$ & \multirow{3}{*}{$F\left(\mathrm{pn}^{2}\right)$} & \multirow{3}{*}{ CONTRASTE } \\
\hline & $(n=61)$ & $(n=79)$ & $(n=38)$ & & \\
\hline & $M \pm D P$ & $M \pm D P$ & $M \pm D P$ & & \\
\hline Desempenho no jogo & $0.48 \pm 0.19$ & $0.54 \pm 0.18$ & $0.65 \pm 0.16$ & $10.89 * * \times .11$ & $\mathrm{EE}>\mathrm{ME}, \mathrm{BE}$ \\
\hline
\end{tabular}

Informação longitudinal: Contraste por coortes de idade

Tomada de decisão, execução motora e resultado da ação

Com base no delineamento longitudinal-misto do INEX foi possível estudar a mudança que ocorreu entre os anos 2018 e 2019 nos três índices (índice da tomada de decisão, execução motora e resultado da ação). Os resultados apresentados no quadro 9 e figura 1 mostram que os jovens basquetebolistas das coortes 3 e 4 melhoraram significativamente os valores médios nos três índices de desempenho ao longo do tempo. Por outro lado, um ano de treino e competição parece não ter sido suficiente para que os jogadores mais novos (coortes 1 e 2) e mais velhos (coorte 5) melhorassem de modo significativo os seus valores de índice da tomada de decisão, execução motora e resultado da ação.

\begin{tabular}{|c|c|c|c|c|c|c|}
\hline \multirow{2}{*}{ ÍNDICES } & \multirow{2}{*}{ COORTES } & 2018 & 2019 & \multirow{2}{*}{$\begin{array}{l}\text { DIFERENÇA } \\
\text { DE MÉDIAS }\end{array}$} & \multirow{2}{*}{$t$} & \multirow{2}{*}{ COHEN'S $d$} \\
\hline & & $M \pm D P$ & $M \pm D P$ & & & \\
\hline \multirow{5}{*}{ 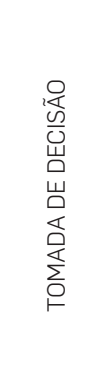 } & Coorte $1(n=12)$ & $0.52 \pm 0.18$ & $0.57 \pm 0.14$ & 0.05 & -0.95 & 0.18 \\
\hline & Coorte $2(n=36)$ & $0.51 \pm 0.19$ & $0.54 \pm 0.17$ & 0.03 & -1.04 & 0.18 \\
\hline & Coorte $3(n=27)$ & $0.53 \pm 0.18$ & $0.63 \pm 0.14$ & 0.10 & $-2.62^{\star}$ & 0.19 \\
\hline & Coorte $4(n=18)$ & $0.61 \pm 0.16$ & $0.74 \pm 0.12$ & 0.13 & $-3.78^{* *}$ & 0.14 \\
\hline & Coorte $5(n=29)$ & $0.74 \pm 0.16$ & $0.71 \pm 0.18$ & -0.02 & 0.64 & 0.18 \\
\hline \multirow{5}{*}{ 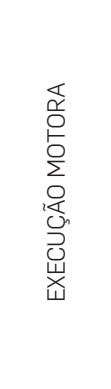 } & Coorte $1(n=12)$ & $0.43 \pm 0.25$ & $0.48 \pm 0.22$ & 0.05 & -0.68 & 0.25 \\
\hline & Coorte $2(n=36)$ & $0.44 \pm 0.21$ & $0.49 \pm 0.19$ & 0.05 & -1.60 & 0.19 \\
\hline & Coorte $3(n=27)$ & $0.45 \pm 0.20$ & $0.57 \pm 0.15$ & 0.11 & $-2.84^{\star *}$ & 0.20 \\
\hline & Coorte $4(n=18)$ & $0.56 \pm 0.21$ & $0.70 \pm 0.13$ & 0.14 & $-3.32^{\star *}$ & 0.18 \\
\hline & Coorte $5(n=29)$ & $0.71 \pm 0.18$ & $0.68 \pm 0.18$ & -0.03 & 0.93 & 0.19 \\
\hline \multirow{5}{*}{ 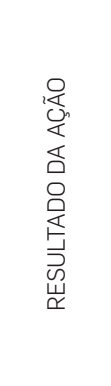 } & Coorte $1(n=12)$ & $0.40 \pm 0.16$ & $0.46 \pm 0.18$ & 0.06 & -1.18 & 0.16 \\
\hline & Coorte $2(n=36)$ & $0.46 \pm 0.18$ & $0.47 \pm 0.16$ & 0.01 & -0.40 & 0.18 \\
\hline & Coorte $3(n=27)$ & $0.50 \pm 0.17$ & $0.54 \pm 0.14$ & 0.04 & -1.28 & 0.18 \\
\hline & Coorte $4(n=18)$ & $0.56 \pm 0.15$ & $0.64 \pm 0.10$ & 0.08 & $-2.42^{*}$ & 0.14 \\
\hline & Coorte $5(n=29)$ & $0.67 \pm 0.14$ & $0.63 \pm 0.16$ & -0.04 & 1.25 & 0.18 \\
\hline
\end{tabular}



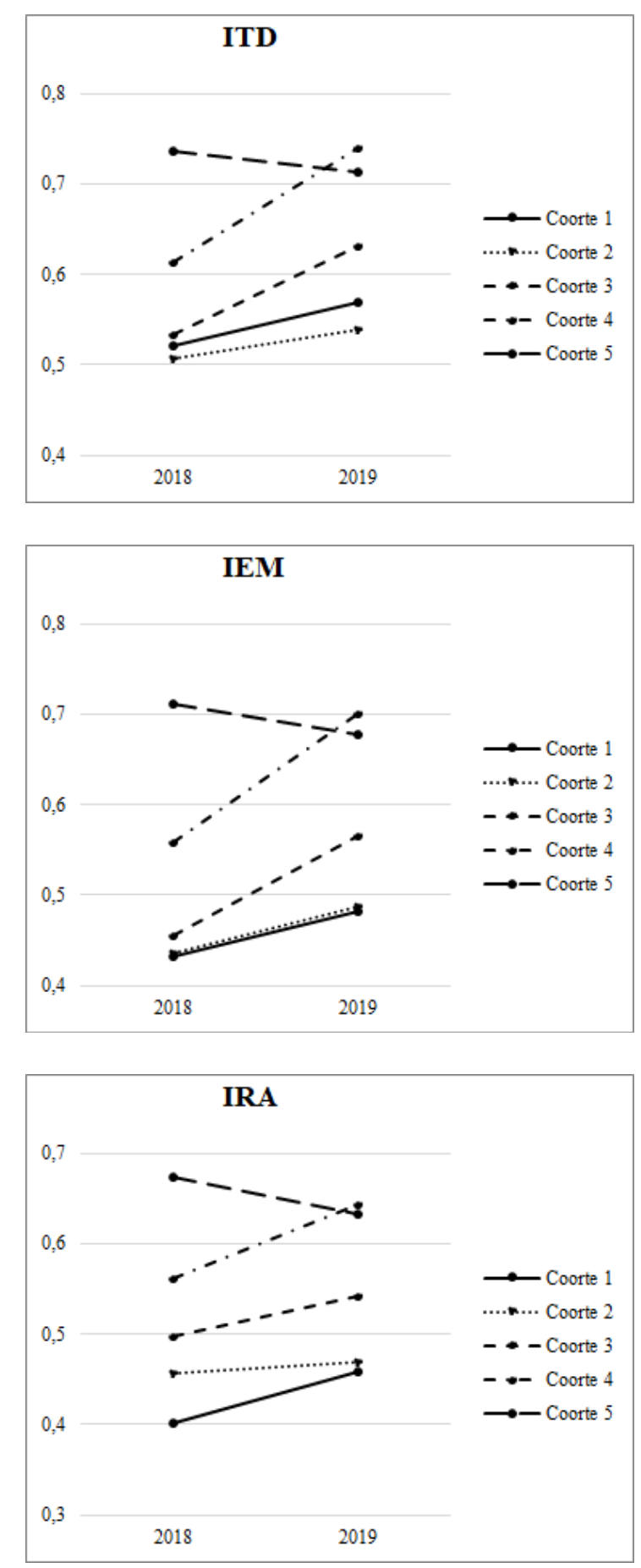

Desempenho no jogo

0 quadro 10 e a figura 2 apresentam o valor do desempenho no jogo dos jovens basquetebolistas das cinco coortes de idade em 2018 e 2019. À semelhança dos índices anteriores, os resultados revelam uma melhoria significativa dos valores médios de desempenho no jogo dos jogadores das coortes 3 e 4, ao passo que a ausência de mudança foi notória nos seus pares das coortes 1,2 e 5 .

QUADRO 10. Resultados dos basquetebolistas no desempenho no jogo, por coorte, em 2018 e 2019

\begin{tabular}{|c|c|c|c|c|c|c|}
\hline \multirow{2}{*}{ ÍNDICES } & \multirow{2}{*}{ COORTES } & 2018 & 2019 & \multirow{2}{*}{$\begin{array}{l}\text { DIFERENÇA } \\
\text { DE MÉDIAS }\end{array}$} & \multirow{2}{*}{$t$} & \multirow{2}{*}{ COHEN'S $d$} \\
\hline & & $M \pm D P$ & $M \pm D P$ & & & \\
\hline \multirow{5}{*}{ 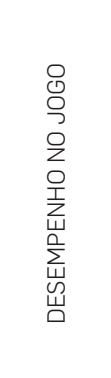 } & Coorte $1(n=12)$ & $0.45 \pm 0.19$ & $0.50 \pm 0.17$ & 0.05 & -0.95 & 0.19 \\
\hline & Coorte $2(n=36)$ & $0.47 \pm 0.19$ & $0.50 \pm 0.16$ & 0.03 & -1.11 & 0.17 \\
\hline & Coorte $3(n=27)$ & $0.50 \pm 0.18$ & $0.58 \pm 0.14$ & 0.08 & $-2.38^{*}$ & 0.18 \\
\hline & Coorte $4(n=18)$ & $0.58 \pm 0.16$ & $0.69 \pm 0.10$ & 0.12 & $-3.46^{* \star}$ & 0.14 \\
\hline & Coorte $5(n=29)$ & $0.71 \pm 0.15$ & $0.67 \pm 0.17$ & -0.03 & 0.98 & 0.18 \\
\hline
\end{tabular}

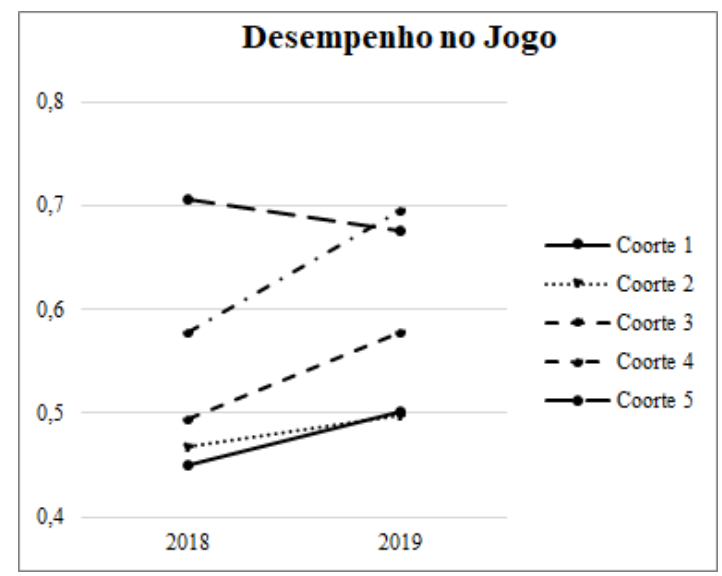

FIGURA 2. : Efeitos do treino e da competição no índice desempenho no jogo dos basquetebolistas das cinco coortes 
Ações (apropriadas e inapropriadas)

0 quadro 11 e a figura 3 apresentam o número de ações apropriadas e inapropriadas realizadas pelos jovens basquetebolistas das cinco coortes em 2018 e em 2019. Os resultados mostram que os jogadores das coortes 2, 3 e 4 foram os que, após um ano de treino e competição, apresentaram uma melhoria significativa do número de ações apropriadas. Quanto às ações inapropriadas, salienta-se uma diminuição do número destas ações nos jogadores das coortes 1 e 4, embora sem significância estatística. Por fim, à exceção da coorte 1 , todos os jovens basquetebolistas aumentaram significativamente o número de ações totais realizadas em contexto de jogo reduzido.

QUADRO 11. Resultados dos basquetebolistas no número de ações (apropriadas, inapropriadas e total) por coorte em 2018 e 2019

\begin{tabular}{|c|c|c|c|c|c|c|}
\hline \multirow{2}{*}{ ÍNDICES } & \multirow{2}{*}{ COORTES } & 2018 & 2019 & \multirow{2}{*}{$\begin{array}{l}\text { DIFERENCCA } \\
\text { DE MÉDIAS }\end{array}$} & \multirow{2}{*}{$t$} & \multirow{2}{*}{ COHEN'S $d$} \\
\hline & & $M \pm D P$ & $M \pm D P$ & & & \\
\hline \multirow{5}{*}{$\begin{array}{l}\frac{0}{0} \\
\frac{1}{\alpha} \\
\frac{\alpha}{0} \\
\frac{\alpha}{2} \\
\frac{\alpha}{\alpha}\end{array}$} & Coorte $1(n=12)$ & $46.08 \pm 21.80$ & $52.25 \pm 19.58$ & 6.17 & -1.47 & 14.52 \\
\hline & Coorte $2(n=36)$ & $47.86 \pm 22.14$ & $56.92 \pm 20.33$ & 9.06 & $-2.52^{\star}$ & 21.54 \\
\hline & Coorte $3(n=27)$ & $53.78 \pm 22.86$ & $80.30 \pm 22.23$ & 26.52 & $-4.53^{* \star \star}$ & 30.45 \\
\hline & Coorte $4(n=18)$ & $60.83 \pm 24.93$ & $86.61 \pm 26.92$ & 25.78 & $-4.26^{* * *}$ & 25.66 \\
\hline & Coorte $5(n=29)$ & $87.31 \pm 25.99$ & $97.55 \pm 34.39$ & 10.24 & -1.61 & 34.18 \\
\hline \multirow{5}{*}{ 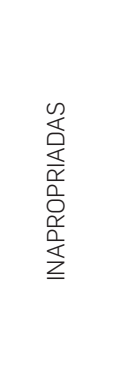 } & Coorte $1(n=12)$ & $53.75 \pm 19.34$ & $53.33 \pm 27.12$ & -0.42 & 0.05 & 31.85 \\
\hline & Coorte $2(n=36)$ & $53.11 \pm 22.44$ & $57.64 \pm 22.70$ & 4.53 & -1.13 & 24.12 \\
\hline & Coorte $3(n=27)$ & $51.63 \pm 16.43$ & $57.89 \pm 21.82$ & 6.26 & -1.49 & 21.83 \\
\hline & Coorte $4(n=18)$ & $42.61 \pm 17.08$ & $36.50 \pm 12.48$ & -6.11 & 1.63 & 15.87 \\
\hline & Coorte $5(n=29)$ & $34.97 \pm 16.95$ & $43.90 \pm 20.91$ & 8.93 & -2.00 & 24.00 \\
\hline \multirow{5}{*}{$\begin{array}{l}\overrightarrow{\vec{E}} \\
\stackrel{\circ}{\circ}\end{array}$} & Coorte $1(n=12)$ & $99.83 \pm 19.23$ & $105.58 \pm 30.78$ & 5.75 & -0.65 & 30.90 \\
\hline & Coorte $2(n=36)$ & $100.97 \pm 23.20$ & $114.56 \pm 24.97$ & 13.58 & $-2.74^{*}$ & 29.80 \\
\hline & Coorte $3(n=27)$ & $105.41 \pm 18.62$ & $138.19 \pm 24.13$ & 32.78 & $-5.69^{* * *}$ & 29.94 \\
\hline & Coorte $4(n=18)$ & $103.44 \pm 23.28$ & $123.11 \pm 28.89$ & 19.67 & $-2.84^{*}$ & 29.41 \\
\hline & Coorte $5(n=29)$ & $122.28 \pm 21.73$ & $141.45 \pm 25.02$ & 19.17 & $-2.89^{\star *}$ & 35.76 \\
\hline
\end{tabular}
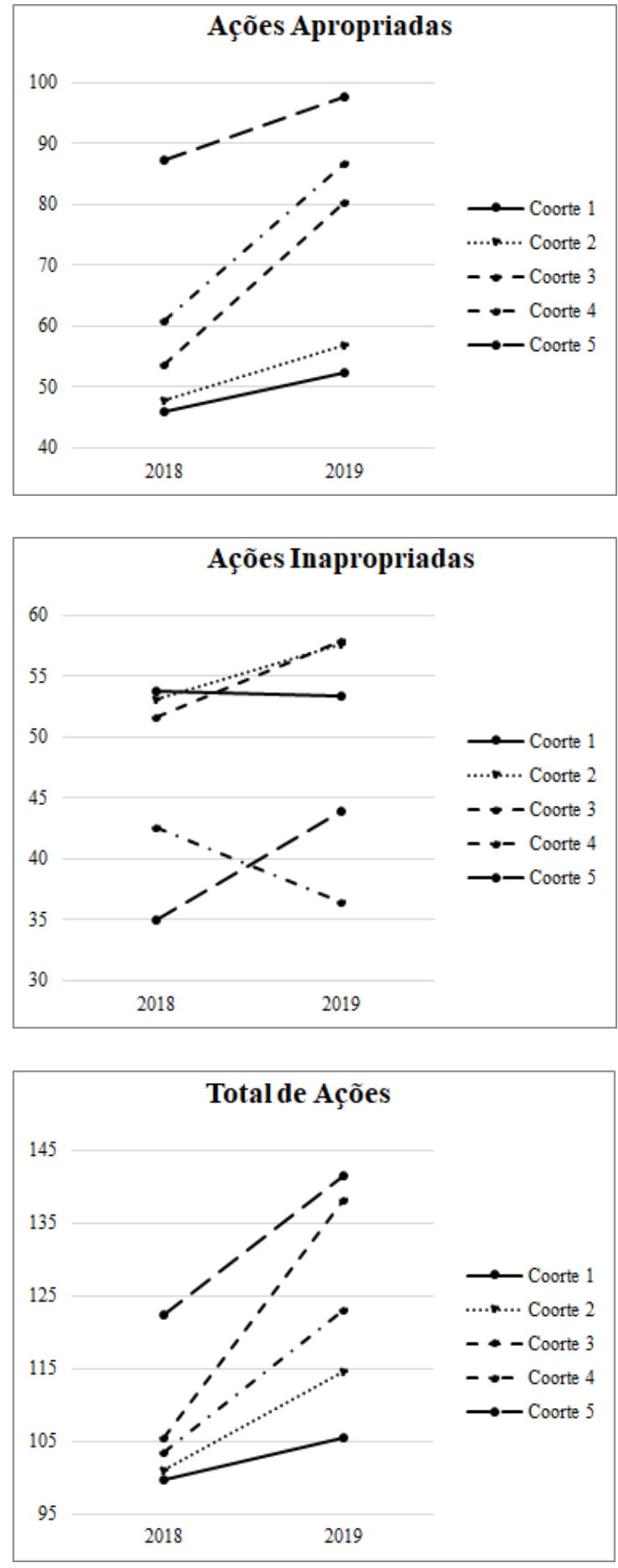

FIGURA 3. Efeitos do treino e da competição no número de ações (apropriadas, inapropriadas e totais) dos basquetebolistas das cinco coortes 
CONCLUSÕES

Ao treinador de basquetebol compete planear, dirigir e avaliar o processo de treino e de competição dos seus atletas. Este processo será tanto mais enriquecedor quanto mais melhor informação tiver sobre a evolução do desempenho técnico-tático dos seus atletas. Por conseguinte, no presente estudo, analisámos de duas formas distintas (informação transversal e informação longitudinal) os índices de tomada de decisão, de execução motora e do resultado da ação, de forma a obter informações relevantes acerca dos níveis de desempenhos dos jogadores em cada uma das respetivas componentes, para além do seu desempenho no jogo.

Genericamente, a partir do primeiro tipo de informação foi possível apurar o predomínio de comportamentos adequados nas três componentes (tomada de decisão, execução motora e resultado da ação), porém com um melhor comportamento dos basquetebolistas mais velhos (coortes 4 e 5) e mais experientes (elevada experiência). Esta evidência redundou num melhor desempenho no jogo destes jogadores mais velhos quando comparados com os seus pares mais novos (coortes 1,2 e 3 ) e menos experientes (baixa e moderada experiência).

Porém, aquando da análise da mudança centrada nos diferentes componentes e no desempenho do jogo, percebemos que os efeitos do treino e da competição apenas se fizeram sentir de forma acentuada nos atletas com idades intermédias na ordenação da nossa amostra (coortes 3 e 4). De facto, o que aqui se percebe são os maiores níveis de adaptação ao treino destes basquetebolistas comparativamente aos seus pares, uns menos experientes (coortes 1 e 2 ) e outros mais experientes (coorte 5). As razões desta evidência poderão expressar, por um lado, o nível de imaturidade no conhecimento do jogo dos atletas mais novos, e por outro, um conhecimento do jogo mais vasto dos atletas mais velhos, ambas particularidades que poderão justificar a menor sensibilidade destes jovens basquetebolistas aos efeitos do treino sistemático. Contudo, convém deixar claro que caso a intensidade dos estímulos não seja suficientemente desafiadora, então as desejadas adaptações poderão não ocorrer. De todo o modo, no nosso estudo não nos foi possível realizar qualquer controlo desta natureza.

De seguida, apresentam-se quatro comentários acerca dos índices em estudo, bem como sobre o desempenho no jogo.

\section{Tomada de decisão}

A tomada de decisão é uma capacidade essencial para o sucesso dos atletas no basquetebol. Corresponde à seleção do modo correto de agir, através da avaliação de informações relevantes e rápida seleção da melhor ação, aliada às experiências passadas, "vividas" no processo de treino e nas situações de jogo. Bons decisores são fundamentais no basquetebo e uma tomada de decisão eficaz pode ser a diferença entre o sucesso e o fracasso no jogo. De maneira geral, os jovens basquetebolistas do Projeto INEX apresentaram níveis adequados de desempenho nesta componente. Os mais velhos e experientes (coortes 4 e 5) demonstraram predominância de desempenho adequado na tomada de decisão em comparação com os das coortes 1,2 e 3, por certo uma consequência do maior tempo de prática desportiva.

Porém, no plano da análise da mudança, a melhoria expressiva da performance ocorreu apenas em atletas com uma margem de crescimento substantiva (os atletas das coortes 3 e 4), ou seja, aqueles capazes de acomodarem os ganhos induzidos pelo treino e pela competição. Nos outros atletas (uns mais novos - coorte 1 e 2, e outros mais velhos - coorte 5), os efeitos adaptativos ao treino e à competição foram insuficientes para que ocorresse verdadeira mudança. De resto, o desenvolvimento dos jovens jogadores está relacionado com a quantidade e à qualidade das situações desportivas em que estão envolvidos e que vivenciam ao longo da fascinante viagem pelos múltiplos caminhos (por vezes inóspitas) da sua modalidade desportiva.

\section{Execução motora}

Os resultados da execução motora, isto é, a habilidade para a execução correta dos fundamentos técnicos do jogo, permitem concluir que a maioria dos basquetebolistas tiveram um desempenho adequado, com supremacia dos pertencentes às coortes 4 e 5 . De todo o modo, a razão de os jogadores mais experientes apresentarem melhor IEM, relativamente aos menos experientes, deve-se provavelmente ao facto de estarem envolvidos num processo de treino mais elaborado, sujeitos à realização sistemática e prolongada de exercícios de fixação e aplicação da técnica, e tal facto poder justificar o melhor desempenho dos escalões mais avançados da formação nesta componente. Os níveis de eficiência mais elevados dos atletas mais experientes poderão ser igualmente justificados por um maior desenvolvimento da sua coordenação motora. Além disso, diferenças no estatuto maturacional e nos parâmetros físicos e psicológicos relacionados a cada coorte de idade, as quais influenciam os seus padrões técnicos e táticos, podem também justificar os resultados favoráveis aos basquetebolistas mais velhos e mais experientes. Tal corresponde a jovens já integrados numa fase de formação/preparação mais avançada, onde os treinos são mais intensos e a competição mais alargada.

Por outro lado, tal como na tomada de decisão, também aqui a análise da mudança mostrou uma melhoria clara da performance nos atletas das coortes 3 e 4, provavelmente aqueles que apresentam uma maior margem de progressão atendendo aos desejados efeitos adaptativos do treino e da competição. 


\section{Resultado da ação}

O resultado da ação, isto é, a eficácia no jogo, resulta da execução da habilidade motora de acordo com os propósitos das ações do jogo. Os resultados mostraram um desempenho adequado, sobretudo dos basquetebolistas das coortes 4 e 5 , resultado igualmente confirmado pelo maior número de ações apropriadas realizadas pelos atletas destas mesmas coortes. Estes resultados podem ser explicados, em certa medida, pelo facto dos atletas mais novos (coortes 1,2 e 3) estarem numa fase mais inicial de desenvolvimento físico e cognitivo e, consequentemente, da sua formação técnico-tática. Tal conjetura poderá significar que os seus níveis de eficácia estão pouco desenvolvidos e, por isso, se tratar de atletas "pouco consistentes" (ainda em fase de formação bastante inicial) quando comparados com os basquetebolistas mais velhos e mais experientes.

Relativamente à análise da mudança, os argumentos anteriormente apresentados continuam a parecer-nos válidos para justificar também aqui a vantagem dos atletas com idades intermédias na ordenação da nossa amostra (coortes 3 e 4) comparativamente aos mais novos (coorte 1 ) e aos mais velhos (coorte 5).

\section{Desempenho no jogo}

Os níveis de desempenho no jogo dos jovens basquetebolistas mostraram-se de acordo com as circunstâncias temporais da sua formação. Ou seja, os atletas mais velhos e com mais anos de prática apresentaram melhores valores médios de Desempenho no Jogo comparativamente com os atletas mais novos e com menos anos de prática. Tal evidência pode ter a ver com o facto de os jogadores com mais anos de prática (mais experientes) demonstrarem um desempenho mais apropriado em comparação com os menos experientes, em virtude de estarem há mais tempo envolvidos com a prática sistemática do treino e da competição. É, aliás, sabido que um tempo longo de prática organizada e constante na modalidade (prática deliberada) permite uma melhoria do desempenho no jogo (e também nas três componentes de rendimento em estudo - índice da tomada de decisão, índice de execução motora e índice de resultado da ação). Uma vez que os atletas mais experientes conseguem localizar e identificar as situações de jogo de maneira mais eficaz e rápida, é de crer que também se ajustem mais rápida e adequadamente às exigências do jogo, o que pode ajudar a explicar o melhor desempenho destes atletas.

De todo o modo, o argumento anterior não colhe quando nos centramos na análise da mudança. De facto, no plano do desempenho no jogo (e tal como já referido para os Índices analisados), os efeitos do treino e da competição foram mais notórios nos atletas das coortes 3 e 4. As razões para tal ocorrência são, do nosso ponto de vista, exatamente as mesmas já expressas anteriormente. Resta sublinhar uma vez mais a importância da qualidade dos estímulos em todo o processo de treino e os seus efeitos na elevação do nível da performance desportiva dos atletas.
Por fim, é apresentado um conjunto de questões que visam esclarecer dúvidas, bem como refletir sobre aspetos decorrentes dos principais resultados deste trabalho. Dirige-se essencialmente aos treinadores de jovens atletas e a todos aqueles que se interessam por esta temática.

1. Qual a importância para o treinador da análise pormenorizada das ações técnico-táticas do jogador de basquetebol?

Este tipo de análise contribui para fornecer informações úteis aos treinadores a respeito da evolução individual do jogador no processo de formação desportiva (a longo prazo). No que diz respeito à formação do jogador de basquetebol, principalmente nos escalões mais baixos, é recomendável que os treinadores centrem as suas preocupações mais no ensino dos fundamentos do jogo, valorizando a leitura do jogo e a execução correta, e menos no ensino de sistemas de jogo complexos.

2. Mais anos de prática, mais experiência, concorrem para um melhor desempenho no jogo? Os resultados assim o indicam. Por isso, é importante o treinador reter que o objetivo da prática deve ser melhorar o desempenho do jogador e apoiar a transferência para o jogo dos conhecimentos adquiridos no treino.

3. Qual a estratégia para melhorar as habilidades técnicas dos atletas?

A questão pode ser colocada do ponto de vista da eficiência, isto é, da execução correta da habilidade numa perspetiva essencialmente mecânica. A ideia será então a de, desde cedo, colocar os praticantes perante situações que solicitem o domínio cognitivo-tático e o domínio técnico. No entanto, os treinadores devem colocar os jogadores perante contextos variáveis, solicitando formas de execução variadas, i.e., que integrem em simultâneo as três componentes de uma ação técnico-tática: tomada de decisão, execução motora e resultado da ação. Sublinhar, contudo, o compromisso que os treinadores devem assumir entre o nível de habilidade técnica do praticante e a dificuldade da tarefa.

4. No processo de ensino do basquetebol é recomendável a utilização do jogo reduzido? Tendo em conta o conjunto de recomendações anteriores, realçamos a importância da utilização do jogo reduzido já que possibilita uma maior participação do jogador, uma menor probabilidade para a ocorrência de atitudes passivas, uma mais elevada frequência de contactos com a bola e um maior sucesso na finalização das ações ofensivas e defensivas. 
5. Qual é a expectativa dos treinadores relativamente à resposta ao treino e à competição dos seus atletas?

Quando um treinador planeia um treino para a sua equipa, espera que os efeitos ou que a resposta a esse treino seja igual por parte de todos os elementos. Será que é mesmo assim? De facto, quando olhamos - em termos médios - para a resposta ao treino, é muito provável que essa ideia de "ganhos para todos" seja evidente. No entanto, como mostram os resultados deste estudo, é nítida a variação na resposta ao treino e à competição. Nest sentido, importa que os treinadores estejam cientes de que os conteúdos da preparação desportiva devem ser ajustados aos níveis de desenvolvimento dos jogadores, ainda que estes pertençam ao mesmo escalão competitivo.
Baker, J., Côté, J., Abernethy, B. (2003). Sport-specific practice and the development of expert decision-making in team ball sports. Journal of Applied Sport Psychology, 15(1), 12-25.

Beunen, G., Malina, R. M., Van't Hof, M. A., Simons, J Ostyn, M., Renson, R., \& Van Gerven, D. (1988). Adoescent growth and motor performance: A longitudina study of Belgian boys. Human Kinetics.

Bornstein M. H. (1989). Sensitive periods in development. Structural characteristics and causal interpretations. Psychological Bulletin, 105(2), 179-197.

Ellis, J. D., Carron, A. V., \& Bailey, D. A. (1975). Physical performance in boys from 10 through 16 years. Human Biology, 47(3), 263-281.

French, K. E., \& Thomas, J. R. (1987). The relation of knowledge development to children's basketball performance. Journal of Sport Psychology, 9, 15-32.

French, K., Werner, P., Rink, J., Taylor, K., e Hussey, K. (1996). The effects of a 3 - week unit of tactical, skil, or combined tactical and skill instruction on badminton performance of ninth-grade students. Journal of Teaching in Physical Education, 15, 418-438.

Gallagher, J. D. French, K. E. Thomas, K. T. e Thomas, J. R. (1996). Expertise in youth sport: Relations be tween knowledge and skill. In F. L. Smoll \& R. E. Sm ith (Eds.). Children and youth sport: A biopsychosocial perspective (pp. 338-358). Brown \& Benchmark. Guimarães, E., Baxter-Jones, A., Pereira, S., Garbeloto, F. Freitas, D. Janeira, M. A. Tani, G., Katzmarzyk. P. T. Silva, S., Bailey, D. A., Mirwald, R. L., \& Maia, J. (2020) Patterns of physical performance spurts during adolescence: A cross-cultural study of Canadian, Brazilian and Portuguese boys. Annals of Human Biology, 47(4). 346-354.

Gumarães, E., Maia, J., Williams, M. Sousa, F., Santos, E., Tavares, F., Janeira, M. A., \& Baxter-Jones, A. (2021). Muscular strength spurts in adolescent male basketbal players: The INEX Study. International Journal of En ronmental Research and Public Health, 18(2), 776 Grehaigne, J. F., Godbout, P., \& Bouthier D (2001) The teaching and learning of decision making in team sports. Quest, 53, 59-76.
Griffin, L., Dodds, P., Placek, J. H., \& Tremino, F. (2001). Middle school students' conceptions of soccer: their solutions to tactical problems. Journal of Teaching in Physical Education, 20(4). 324-340.

Janeira, M. A. \& Maia, J. (1998). Game intensity in basketball: An interactionist view linking time-motion analysis, lactate concentration and heart rate. Cooching and Sport Science Journal, 3(2), 26-30.

Malina, R. M. (2008). Skill acquisition in childhood and adolescence. In H. Hebestreit \& O. Bar-Or (Eds.), The young athlete (pp. 96-111). Blackwell Publishing. McPherson, S. L. (1999). Expert-novice differences in performance skills and problem representations of youth and adults during tennis competition. Research Quarterly for Exercise and Sport, 70(3), 233-251

Mcpherson, S. L., \& French, K. E. (1991). Changes in cognitive strategies and motor skills in tennis. Journal of Sport and Exercise Psychology, 13(1), 26-41. Oslin, J. L., Mitchell, S. A., \& Griffin, L. L. (1998). The Game Performance Assessment Instrument (GPAl) Development and preliminary validation. Journal of Teaching in Physical Education, 17(2), 231-243.

Philippaerts, R. M., Vaeyens, R., Janssens, M., Van Renterghem, B., Matthys, D., Craen, R., Bourgois, J., Vrijens, J., Beunen, G., \& Malina, R. M. (2006). The relationship between peak height velocity and physical performance in youth soccer players. Journal of Sports Sciences. 24(3), 221-230.

Silva, S., Mendes, H., Freitas, D., Prista, A. Tani, G., Katzmarzyk, P. T., Baxter-Jones, A., Valdivia, A. B., \& Maia J. (2019). Development of physical performance tasks during rapid growth in Brazilian children: The Carir Healthy Growth Study. International Journal of Environmental Research and Public Health, 16(24), 5029.

Tallir. I. B. Lenoir, M. Valcke, M. \& Musch, E. (2007). Do alternative instructional approaches result in different game performance learning outcomes? Authentic assessment in varying game conditions. International Journal of Sport Psychology, 38(3), 263-282.

Tavares, F. (1995). Estudo da capacidade de decisão tactica em jogadores de basquetebol seniores e cadetes. Revista 0 Treinador, 32 
Thomas, K. T., Gallagher, J. D., \& Thomas, J. R. (2001). Motor development and skill acquisition during childhood and adolescence. In R. N. Singer, H. A. Hausenblas, \& C. M. Janelle. (Eds.). Handbook of sport psychology (2nd Ed.). John Wiley.

Turner, A. P., \& Martinek, T. J. (1992). A comparative analysis of two models for teaching games [Technique approach and game centered (tactical focus) approach]. International Journal of Physical Education, 29, 15-31.

Williams, M., Ford, P., Eccles, D., \& Ward, P. (2010). Perceptual-cognitive expertise in sport and its acquisition: Implications for applied cognitive psychology. Applied Cognitive Psychology, 25, 432-442.

Yagüe, P. H., \& De La Fuente, J. M. (1998). Changes in height and motor performance relative to peak height velocity: A mixed-longitudinal study of Spanish boys and girls. American Journal of Human Biology, 10(5), 647-660.
ANEXO. Resultados dos basquetebolistas nos índices das categorias e subcategorias (tomada de decisão, execução motora, resultado da ação) por coorte no baseline

\begin{tabular}{|c|c|c|c|c|c|c|c|}
\hline \multirow{3}{*}{ ÍNDICES } & $\begin{array}{l}\text { COORTE } 1 \\
\text { (C1) }\end{array}$ & $\begin{array}{l}\text { COORTE } 2 \\
\text { (C2) }\end{array}$ & $\begin{array}{c}\text { COORTE } 3 \\
(\mathrm{C} 3)\end{array}$ & $\begin{array}{c}\text { COORTE } 4 \\
\text { (C4) }\end{array}$ & $\begin{array}{l}\text { COORTE } 5 \\
\text { (C5) }\end{array}$ & \multirow{3}{*}{$F\left(\mathrm{pn}^{2}\right)$} & \multirow{3}{*}{ CONTRASTE } \\
\hline & $(n=18)$ & $(n=45)$ & $(n=37)$ & $(n=32)$ & $(n=46)$ & & \\
\hline & $M \pm D P$ & $M \pm D P$ & $M \pm D P$ & $M \pm D P$ & $M \pm D P$ & & \\
\hline \multicolumn{8}{|l|}{ RECEÇÃO/PARAGEM } \\
\hline Tomada de decisão & $0.76 \pm 0.25$ & $0.64 \pm 0.32$ & $0.69 \pm 0.29$ & $0.73 \pm 0.22$ & $0.75 \pm 0.25$ & $1.27 n s(.03)$ & --- \\
\hline Execução motora & $0.55 \pm 0.35$ & $0.45 \pm 0.34$ & $0.45 \pm 0.33$ & $0.60 \pm 0.33$ & $0.63 \pm 0.29$ & $2.56^{\star}(0.06)$ & --- \\
\hline Resultado da ação & $0.30 \pm 0.29$ & $0.23 \pm 0.24$ & $0.25 \pm 0.25$ & $0.32 \pm 0.34$ & $0.52 \pm 0.33$ & $6.96^{\star \star \star}(.14)$ & $\mathrm{C} 5>\mathrm{C} 4, \mathrm{C} 3, \mathrm{C} 2$ \\
\hline \multicolumn{8}{|l|}{ PASSE } \\
\hline Tomada de decisão & $0.87 \pm 0.18$ & $0.79 \pm 0.21$ & $0.81 \pm 0.23$ & $0.82 \pm 0.22$ & $0.89 \pm 0.18$ & $1.64 n s(.04)$ & --- \\
\hline Execução motora & $0.62 \pm 0.38$ & $0.52 \pm 0.30$ & $0.57 \pm 0.32$ & $0.66 \pm 0.30$ & $0.79 \pm 0.23$ & $\left.5.14^{\star * \star} . .11\right)$ & $\mathrm{C} 5>\mathrm{C} 3, \mathrm{C} 2$ \\
\hline Resultado da ação & $0.68 \pm 0.35$ & $0.66 \pm 0.27$ & $0.70 \pm 0.27$ & $0.81 \pm 0.22$ & $0.88 \pm 0.18$ & $5.31^{\star \star *}(.12)$ & $\mathrm{C} 5>\mathrm{C} 3, \mathrm{C} 2, \mathrm{Cl}$ \\
\hline \multicolumn{8}{|l|}{ DRIBLE } \\
\hline Tomada de decisão & $0.49 \pm 0.32$ & $0.29 \pm 0.24$ & $0.23 \pm 0.22$ & $0.34 \pm 0.28$ & $0.52 \pm 0.31$ & $7.74(0.16)^{* * *}$ & $\mathrm{C} 5>\mathrm{C} 4, \mathrm{C} 3, \mathrm{C} 2$ \\
\hline Execução motora & $0.68 \pm 0.34$ & $0.54 \pm 0.35$ & $0.60 \pm 0.34$ & $0.69 \pm 0.25$ & $0.75 \pm 0.26$ & $2.98(0.07)^{\star}$ & $\mathrm{C} 5>\mathrm{C} 2$ \\
\hline Resultado da ação & $0.83 \pm 0.22$ & $0.70 \pm 0.30$ & $0.73 \pm 0.28$ & $0.80 \pm 0.22$ & $0.81 \pm 0.26$ & $1.45 n s(.03)$ & --- \\
\hline \multicolumn{8}{|l|}{ LANÇAMENTO } \\
\hline Tomada de decisão & $0.61 \pm 0.24$ & $0.62 \pm 0.27$ & $0.59 \pm 0.26$ & $0.72 \pm 0.20$ & $0.75 \pm 0.23$ & $3.43^{*}(.08)$ & $\mathrm{C} 5>\mathrm{C} 3$ \\
\hline Execução motora & $0.38 \pm 0.22$ & $0.41 \pm 0.29$ & $0.36 \pm 0.24$ & $0.45 \pm 0.29$ & $0.58 \pm 0.26$ & $4.11^{\star \star}(.09)$ & $\mathrm{C} 5>\mathrm{C} 3, \mathrm{C} 2$ \\
\hline Resultado da ação & $0.29 \pm 0.19$ & $0.35 \pm 0.30$ & $0.31 \pm 0.25$ & $0.34 \pm 0.23$ & $0.40 \pm 0.26$ & 1.1.ns (.03) & --- \\
\hline \multicolumn{8}{|l|}{$\begin{array}{l}\text { MOVIMENTO SEM } \\
\text { BOLA }\end{array}$} \\
\hline Tomada de decisão & $0.61 \pm 0.35$ & $0.58 \pm 0.33$ & $0.62 \pm 0.33$ & $0.64 \pm 0.32$ & $0.64 \pm 0.34$ & $0.31 n s(.01)$ & --- \\
\hline Execução motora & $0.33 \pm 0.34$ & $0.37 \pm 0.35$ & $0.44 \pm 0.35$ & $0.50 \pm 0.41$ & $0.64 \pm 0.36$ & $3.98^{* \star}(.09)$ & $\mathrm{C} 5>\mathrm{C} 2, \mathrm{Cl}$ \\
\hline Resultado da ação & $0.62 \pm 0.33$ & $0.64 \pm 0.37$ & $0.74 \pm 0.27$ & $0.82 \pm 0.25$ & $0.82 \pm 0.28$ & $3.11^{*}(.07)$ & --- \\
\hline
\end{tabular}


ANEXO. Resultados dos basquetebolistas nos índices das categorias e subcategorias (tomada de decisão, execução motora, resultado da ação) por coorte no baseline (cont)

\begin{tabular}{|c|c|c|c|c|c|c|c|}
\hline \multirow{3}{*}{ ÍNDICES } & $\begin{array}{c}\text { COORTE } 1 \\
\text { (C1) }\end{array}$ & $\begin{array}{c}\text { COORTE } 2 \\
\text { (C2) }\end{array}$ & $\begin{array}{c}\text { COORTE } 3 \\
(\mathrm{C} 3)\end{array}$ & $\begin{array}{c}\text { COORTE } 4 \\
\text { (C4) }\end{array}$ & $\begin{array}{c}\text { COORTE } 5 \\
\text { (C5) }\end{array}$ & \multirow{3}{*}{$F\left(p n^{2}\right)$} & \multirow{3}{*}{ CONTRASTE } \\
\hline & $(n=18)$ & $(n=45)$ & $(n=37)$ & $(n=32)$ & $(n=46)$ & & \\
\hline & $M \pm D P$ & $M \pm D P$ & $M \pm D P$ & $M \pm D P$ & $M \pm D P$ & & \\
\hline \multicolumn{8}{|l|}{$\begin{array}{l}\text { RESSALTO } \\
\text { OFENSIVO } \\
\end{array}$} \\
\hline Tomada de decisão & $0.39 \pm 0.42$ & $0.28 \pm 0.31$ & $0.44 \pm 0.36$ & $0.42 \pm 0.34$ & $0.54 \pm 0.37$ & $2.84^{\star}(.07)$ & $\mathrm{C} 5>\mathrm{C} 2$ \\
\hline Execução motora & $0.81 \pm 0.37$ & $0.72 \pm 0.37$ & $0.85 \pm 0.32$ & $0.68 \pm 0.48$ & $0.81 \pm 0.31$ & $0.84 n s(.03)$ & --- \\
\hline Resultado da ação & $0.65 \pm 0.44$ & $0.72 \pm 0.41$ & $0.80 \pm 0.36$ & $0.57 \pm 0.45$ & $0.71 \pm 0.38$ & $1.01 n s(.04)$ & --- \\
\hline \multicolumn{8}{|l|}{$\begin{array}{l}\text { RESSALTO } \\
\text { DEFENSIVO } \\
\end{array}$} \\
\hline Tomada de decisão & $0.41 \pm 0.37$ & $0.42 \pm 0.34$ & $0.55 \pm 0.33$ & $0.59 \pm 0.41$ & $0.66 \pm 0.32$ & $3.15 *(.07)$ & $\mathrm{C} 5>\mathrm{C} 2$ \\
\hline Execução motora & $0.18 \pm 0.35$ & $0.44 \pm 0.39$ & $0.41 \pm 0.37$ & $0.43 \pm 0.35$ & $0.70 \pm 0.34$ & $6.91^{* \star *}(.16)$ & $\begin{array}{c}\mathrm{C} 5<\mathrm{C} 4, \mathrm{C} 3, \\
\mathrm{C} 2, \mathrm{Cl}\end{array}$ \\
\hline Resultado da ação & $0.40 \pm 0.40$ & $0.54 \pm 0.41$ & $0.71 \pm 0.33$ & $0.61 \pm 0.36$ & $0.77 \pm 0.33$ & $3.88^{\star *}(.10)$ & $\mathrm{C} 5>\mathrm{C} 2, \mathrm{Cl}$ \\
\hline \multicolumn{8}{|l|}{$\begin{array}{l}\text { MARCACGÃO } \\
\text { JOGADOR C/BOLA }\end{array}$} \\
\hline Tomada de decisão & $0.44 \pm 0.26$ & $0.45 \pm 0.33$ & $0.57 \pm 0.30$ & $0.68 \pm 0.20$ & $0.70 \pm 0.26$ & $6.50^{\star \star *}(.13)$ & $\mathrm{C} 5, \mathrm{C} 4>\mathrm{C} 2, \mathrm{C} 1$ \\
\hline Execução motora & $0.24 \pm 0.25$ & $0.34 \pm 0.32$ & $0.42 \pm 0.30$ & $0.50 \pm 0.23$ & $0.56 \pm 0.28$ & $5.93^{\star \star \star}(.12)$ & $\begin{array}{c}\mathrm{C} 4>\mathrm{Cl} ; \\
\mathrm{C} 5>\mathrm{C} 2, \mathrm{Cl}\end{array}$ \\
\hline Resultado da ação & $0.23 \pm 0.22$ & $0.28 \pm 0.31$ & $0.36 \pm 0.27$ & $0.42 \pm 0.20$ & $0.49 \pm 0.27$ & $5.09^{\star \star \star}(.11)$ & $\mathrm{C} 5>\mathrm{C} 2, \mathrm{Cl}$ \\
\hline \multicolumn{8}{|l|}{$\begin{array}{l}\text { MARCACÃ̃O } \\
\text { JOGADOR S/BOLA }\end{array}$} \\
\hline Tomada de decisão & $0.21 \pm 0.34$ & $0.30 \pm 0.40$ & $0.44 \pm 0.38$ & $0.67 \pm 0.37$ & $0.70 \pm 0.39$ & $9.85^{* \star *}(.19)$ & $\begin{array}{c}\mathrm{C} 4>\mathrm{C} 2, \mathrm{Cl} ; \\
\mathrm{C} 5>\mathrm{C} 3, \mathrm{C} 2, \mathrm{C} 1\end{array}$ \\
\hline Execução motora & $0.21 \pm 0.35$ & $0.24 \pm 0.37$ & $0.41 \pm 0.38$ & $0.64 \pm 0.36$ & $0.66 \pm 0.40$ & $10.22^{1 * \times(.20)}$ & $\begin{array}{c}\mathrm{C} 4>\mathrm{C} 2, \mathrm{C} 1 ; \\
\mathrm{C} 5>\mathrm{C} 3, \mathrm{C} 2, \mathrm{C} 1\end{array}$ \\
\hline Resultado da ação & $0.15 \pm 0.31$ & $0.21 \pm 0.35$ & $0.35 \pm 0.36$ & $0.54 \pm 0.37$ & $0.59 \pm 0.39$ & $9.24^{\star * \star}(.18)$ & $\begin{array}{c}\mathrm{C} 4>\mathrm{C} 2, \mathrm{C} 1 ; \\
\mathrm{C} 5>\mathrm{C} 3, \mathrm{C} 2, \mathrm{C} 1\end{array}$ \\
\hline \multicolumn{8}{|l|}{ AJUDA DEFENSIVA } \\
\hline Tomada de decisão & $0.73 \pm 0.47$ & $0.72 \pm 0.42$ & $0.82 \pm 0.37$ & $0.86 \pm 0.33$ & $0.89 \pm 0.29$ & $0.83(0.04)$ & --- \\
\hline Execução motora & $0.50 \pm 0.46$ & $0.78 \pm 0.39$ & $0.81 \pm 0.38$ & $0.87 \pm 0.33$ & $0.79 \pm 0.37$ & $1.37(0.07)$ & --- \\
\hline Resultado da ação & $0.38 \pm 0.44$ & $0.76 \pm 0.41$ & $0.55 \pm 0.50$ & $0.75 \pm 0.40$ & $0.61 \pm 0.44$ & $1.48(0.08)$ & --- \\
\hline
\end{tabular}

AUTORES:

Rafael Bagatin ${ }^{1}$

João Ribeiro

Miguel Ferraz ${ }^{1}$

Rui Ferreira ${ }^{1}$

Matheus Coelho ${ }^{1}$

André Milheiro ${ }^{1}$

Henning Almeida ${ }^{1}$

Tomas Scheiber ${ }^{1}$

Daniel Barreira ${ }^{1}$

${ }^{1}$ Centro de Investigação, Formação,

Intervenção e Inovação em Despo to

(CIFI'D), Faculdade de Desporto,

Universidade do Porto, Portugal

\section{https://doi.org/10.5628/rpcd.21.52.313}

\section{TRAJETÓRIAS DE MUDANÇA DOS INDICADORES RELACIONA- DOS COM O PASSE: UMA ABORDAGEM BASEADA NA ANÁLISE DAS REDES SOCIAIS}

INTRODUÇÃO

As equipas de futebol revelam um conjunto de propriedades estruturais e dinâmicas que se afiguram essenciais para o bom funcionamento e organização em contextos de competição (Ribeiro et al., 2017). Nos últimos anos tem-se verificado um número crescente de estudos que têm empregado a análise das redes sociais com o objetivo de examinar as propriedades topológicas que governam o funcionamento das equipas de futebol (Duch et al., 2010; Clemente et al., 2014; Gama et al., 2014; Gonçalves et al., 2017; Pina et al., 2017). A análise das redes sociais procura desvendar os padrões comportamentais que emergem das relações interpessoais estabelecidas por pares de jogadores durante a competição (Passos et al., 2011). Este método de análise recorre a uma terminologia muito específica, sendo os jogadores concetualizados enquanto "nós" ou "vértices" da rede social, conectados por diferentes tipos de relações intrapessoais (neste estudo, será considerado o passe como o meio de comunicação explícita através da qual se verifica a transmissão da bola entre pares de jogadores)

Estudos prévios (e.g., Grund, 2010) têm procurado escrutinar a associação entre algumas propriedades das redes de passes, nomeadamente, a densidade (i.e., os passes estão equitativamente distribuídos por pares de jogadores) e centralidade (i.e., os passes estão distribuídos de modo desequilibrado - alguns jogadores são requisitados com maior re- e longitudinal.

Futebol 